\title{
Metabolic serum biomarkers for the prediction of cancer: a follow-up of the studies conducted in the Swedish AMORIS study
}

\author{
Cecilia Bosco ${ }^{1,2}$, Wahyu Wulaningsih", ${ }^{1,}$ Jennifer Melvin ${ }^{1}$, Aida Santaolalla1, Mario De Piano ${ }^{1}$, Rhonda Arthur ${ }^{1}$ and \\ Mieke Van Hemelrijck ${ }^{1}$
}

${ }^{1}$ King's College London, Division of Cancer Studies, Cancer Epidemiology Group, Research Oncology, 3rd floor, Bermondsey wing, Guy's Hospital, London SE1 9RT, UK

${ }^{2}$ Both authors contributed equally

Correspondence to: Mieke Van Hemelrijck. Email: mieke.vanhemelrijck@kcl.ac.uk

\begin{abstract}
The Swedish Apolipoprotein MOrtality RISk study (AMORIS) contains information on more than 500 biomarkers collected from 397,443 men and 414,630 women from the greater Stockholm area during the period 1985-1996. Using a ten-digit personal identification code, this database has been linked to Swedish national registries, which provide data on socioeconomic status, vital status, cancer diagnosis, comorbidity, and emigration. Within AMORIS, 18 studies assessing risk of overall and site-specific cancers have been published, utilising a range of serum markers representing glucose and lipid metabolism, immune system, iron metabolism, liver metabolism, and bone metabolism. This review briefly summarises these findings in relation to more recently published studies and provides an overview of where we are today and the challenges of observational studies when studying cancer risk prediction.

Overall, more recent observational studies supported previous findings obtained in AMORIS, although no new results have been reported for serum fructosamine and inorganic phosphate with respect to cancer risk. A drawback of using serum markers in predicting cancer risk is the potential fluctuations following other pathological conditions, resulting in non-specificity and imprecision of associations observed. Utilisation of multiple combination markers may provide more specificity, as well as give us repeated instead of single measurements. Associations with other diseases may also necessitate further analytical strategies addressing effects of serum markers on competing events in addition to cancer. Finally, delineating the role of serum metabolic markers may generate valuable information to complement emerging clinical studies on preventive effects of drugs and supplements targeting metabolic disorders against cancer.
\end{abstract}

Keywords: cancer, serum lipids, serum glucose, C-reactive protein, leukocytes, IgE, calcium, iron, gamma-glutamyl transferase

Published: 23/07/2015

Received: 05/11/2014

ecancer 2015, 9:555 DOI: 10.3332/ecancer.2015.555

Copyright: (c) the authors; licensee ecancermedicalscience. This is an Open Access article distributed under the terms of the Creative Commons Attribution License (http://creativecommons.org/licenses/by/3.0), which permits unrestricted use, distribution, and reproduction in any medium, provided the original work is properly cited. 


\section{Introduction}

The Swedish AMORIS database is by far one of the largest prospective cohort studies with detailed information on serum biomarkers. Between 1985 and 1996, the Central Automation Laboratory collected and analysed blood samples of 397,443 men and 414,630 women, mainly from the greater Stockholm area [1-4]. All individuals were either healthy individuals referred for clinical laboratory testing as part of a general health checkup or outpatients. This database with information on $>500$ biomarkers has been linked to several Swedish national registries such as the National Cancer Register, the Patient Register, the Cause of Death Register, the consecutive Swedish Censuses during 1970-1990, and the National Register of Emigration. By using the Swedish ten-digit personal identity number one can get information on socioeconomic status, vital status, cancer diagnosis, comorbidity, and emigration.

With respect to cancer outcomes, 18 studies to date investigated the association with serum biomarkers of lipid and glucose metabolism, the immune system, liver metabolism, iron metabolism, and bone metabolism in AMORIS [5-22]. Following a brief overview of the results found for all biomarkers studied in AMORIS, the current review aims to summarise subsequently published epidemiological evidence on these serum biomarkers in relation to risk of cancer development.

\section{Literature review}

For each following subsection we used related medical subject headings (MeSH) terms for the biomarkers studied in AMORIS as well as 'neoplasm'. Both PubMed and Embase were searched only using the date of AMORIS publications as a limitation to ensure that we found all epidemiological evidence published subsequently to our findings in this Swedish prospective cohort. Studies relevant to previous work in AMORIS were selected and included in this review.

\section{Lipid metabolism}

\section{Selected biomarkers}

A wide variety of serum biomarkers allow the investigation into the association between lipid metabolism and cancer. Triglycerides constitute the majority of the lipids in the body, whereas cholesterol is a precursor for plasma membranes, bile salts, steroid hormones, and other specialised molecules. Cholesterol requires lipoproteins to be transported in the blood stream. Low density lipoproteins (LDL) are the main cholesterol carriers and they deliver cholesterol to cells throughout the body [23]. In contrast, high-density lipoproteins (HDL) remove excess cholesterol from blood and tissue. Apolipoproteins A-I and B (ApoA-I and ApoB) are structural proteins of these lipoprotein particles assisting in their transport [24].

Dyslipidaemia, or abnormal lipid metabolism, is thought to be involved in cancer development through a pathway linked to fatty acid synthesis [25-29]. High serum levels of lipid components such as triglycerides, total cholesterol, LDL, and ApoB have also been implicated in development of certain types of cancers such as breast and prostate by stimulating the Akt and AMPK pathways, which are associated with DNA damage and cell proliferation [30-32]. Additionally, hypercholesterolaemia has been shown to up-regulate the activity of transcriptional factors such as Sterol Regulatory Element-Binding Proteins (SREBP) and low-density lipoprotein receptor (LDLr), which promote carcinogenesis $[33,34]$. All these evidence suggests a potential role of serum lipids in the prediction of cancer.

\section{Findings in AMORIS}

We have studied the interplay between glucose, triglycerides, total cholesterol and the associated risk of prostate, kidney, and gastrointestinal cancers $[10,11,14,15]$. Our findings supported the hypothesis that components from the lipid metabolism influence risk of developing cancer, although a greater risk of prostate cancer with increasing triglycerides was only seen in men with higher glucose levels [11].

Low levels of HDL and ApoA-I were also found to be associated with increased prostate cancer risk [14]. Additionally, we studied the link between serum lipids and risk of breast, endometrial, and ovarian cancer [7, 8], and found a positive association between serum triglycerides and risk of endometrial cancer, whereas only a weak inverse relation was observed for breast cancer. 


\section{New epidemiological findings in the literature}

Since the last AMORIS publication, several epidemiological studies have also focused on serum lipid markers and risk of prostate cancer (Table 1). A statistically significant positive association was observed with total cholesterol [35-38], whereas an inverse association was found for triglycerides [39]. When focusing specifically on aggressive prostate cancer, the Cancer Prevention Study II Nutrition Cohort [40] reported that neither total cholesterol, LDL- or HDL-cholesterol were associated with it. Also for gastrointestinal cancers, many more studies have been published. Total cholesterol and triglycerides have been positively associated with risk of colorectal cancer [41, 42], whereas HDL has been found to either have no effect or reduce this risk [43]. Most studies failed to demonstrate any effect of circulating lipids on risk of rectal cancer alone [43-45].

In addition, an increased risk for breast, bladder, and pancreatic cancer has been observed among those with high circulating levels of total cholesterol, triglycerides, LDL, and low circulating levels of HDL [35, 46-49] compared to those with normal levels. In contrast, no statistically significant association was found between lipid components and risk of ovarian cancer in the Metabolic syndrome and Cancer project (Me-Can) [50]. Similarly, null-findings were observed in a prospective cohort study based on a Korean population focusing on cervical, kidney, gall bladder, pancreatic, lung, and oesophageal cancers. However, in the same study when authors analysed serum lipid levels and the associated risk of stomach and liver cancer, they found an inverse association [35]. With respect to the inverse association between ApoA-I and cancer, as observed in AMORIS, four studies corroborated these findings [14, 43, 48, 49, 51].

\section{Where are we today?}

Dyslipidaemia is closely linked to obesity, another emerging risk factor for several cancers [52]. This implies that despite the suggested mechanisms, abnormal lipid metabolism may be a proxy of other lifestyle-related factors underlying carcinogenesis. Nevertheless, there is evidence suggesting that statins, a class of lipid-lowering drug, may suppress cell proliferation and increase apoptosis by inhibiting the action of the enzyme hydroxymethylglutaryl coenzyme A (HMG-CoA) reductase [53-55], further indicating the involvement of lipids in carcinogenesis. The inverse association between ApoA-I and cancer as found in our study was potentially related to not only inflammation [56], but other lifestyle factors such as body mass index (BMI), cigarette smoking, alcohol intake, diabetes, or hypertension influencing the circulating levels of ApoA-I. This lipid biomarker has been shown to be predictive of cardiovascular risk [4,57] and it is thus possible that the oetiological pathway between lipid profiles and atherosclerosis is different from the pathway between lipid profiles and cancer. The strong association between the lipid metabolism and cardiovascular disease also indicates a potential competing risk situation [58], where individuals at risk of cancer may die of cardiovascular disease before being diagnosed with cancer. This urges further studies to address the issue especially when assessing serum lipids in relation to cancer.

\section{Glucose metabolism}

\section{Selected biomarkers}

Disruptions in the glucose metabolism, which encompass an array of metabolic abnormalities such as diabetes, have been linked to chronic diseases including cancer [59]. Serum glucose is the most commonly measured marker of the glucose metabolism, representing current levels of glucose in the circulation. Fructosamine is another commonly used marker and reflects the average level of serum glucose in the previous 10-14 days [60]. Insulin, with elevated levels marking the initial stage of impaired glucose metabolism, has been suggested to be involved in carcinogenesis through its growth-promoting effects on cells [61]. Similar mutagenic effects have been suggested for a closely linked marker, insulin-like growth factor I (IGF-I) [62]. Additionally, serum glucose may directly affect cancer through generation of Advanced Glycation End-products (AGE), which leads to chronic inflammation [63]. Fructosamine, which represents all glycated serum proteins, may therefore also be involved in this mechanism. The role of impaired glucose metabolism in cancer development and survival has been suggested [64], for instance, Hammarsten et al showed in a prospective study of 320 prostate cancer patients that men who died of clinical prostate cancer during follow-up had a higher prevalence of type 2 diabetes $(P<0.035)$ and higher levels of fasting plasma insulin $(P=0.004)[65]$. These results indicated that insulin levels could be used as markers of prostate cancer prognosis and tumour aggressiveness, regardless of the patient's prostate cancer stage, cancer grade, and PSA level. Data from another prospective cohort in Sweden also 
ecancer 2015, 9:555

\begin{tabular}{|c|c|c|c|c|c|c|c|}
\hline 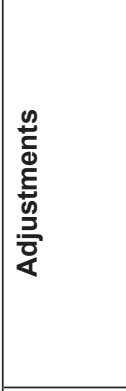 & 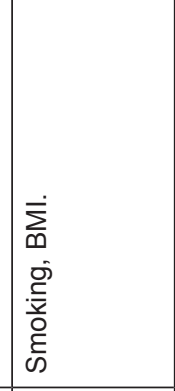 & 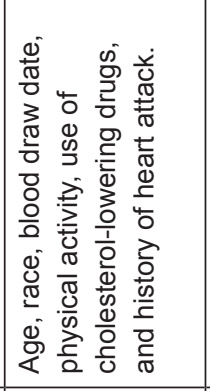 & 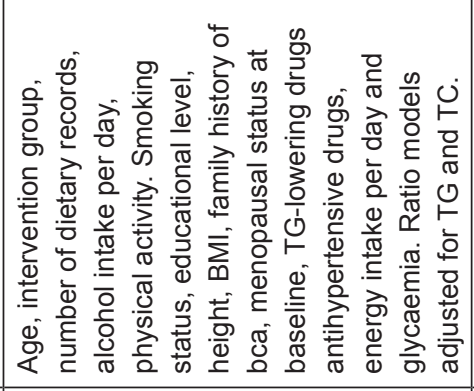 & 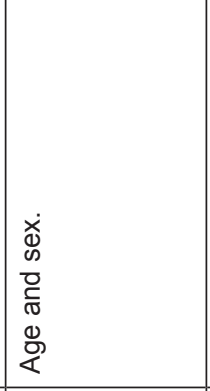 & 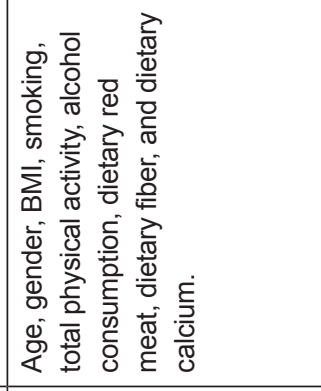 & 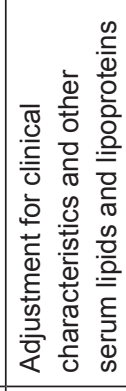 & 1 \\
\hline 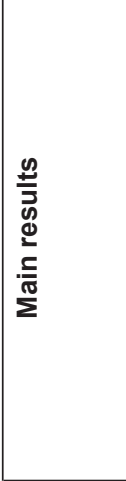 & 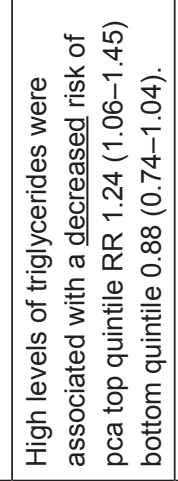 & 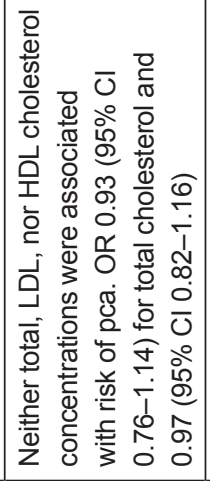 & 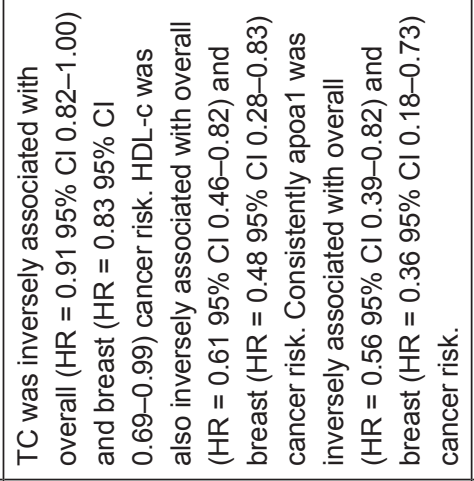 & 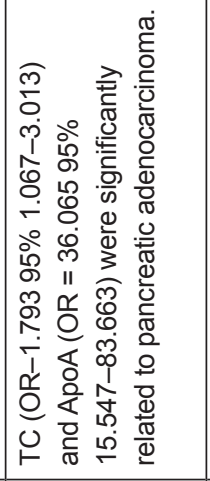 & 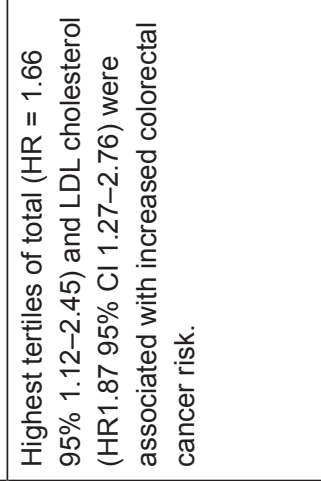 & 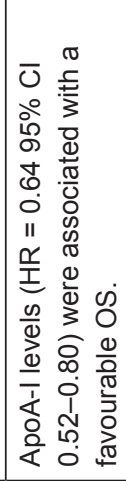 & 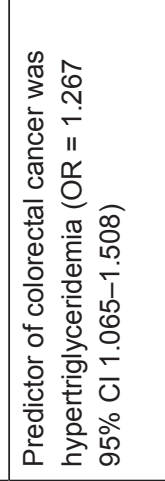 \\
\hline 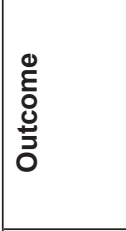 & & 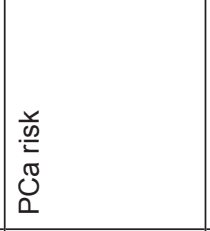 & 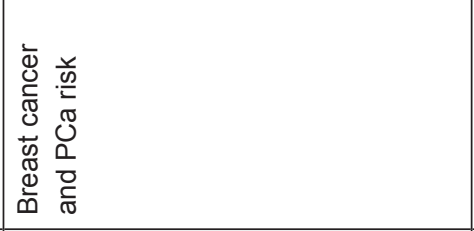 & 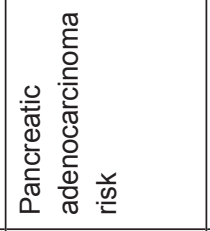 & 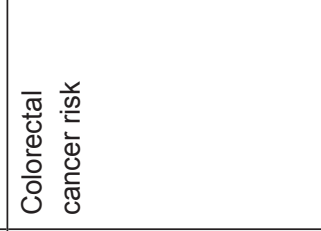 & 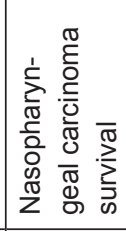 & 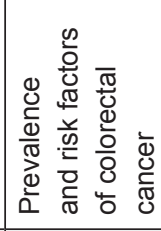 \\
\hline 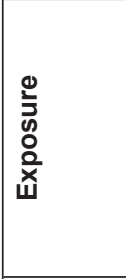 & 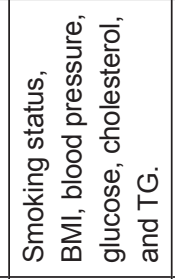 & 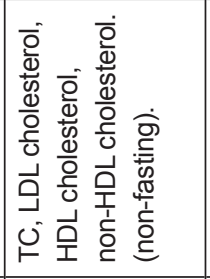 & 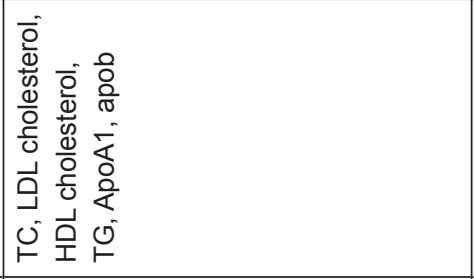 & 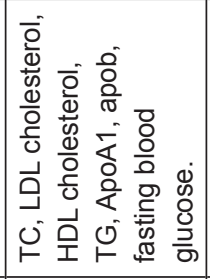 & 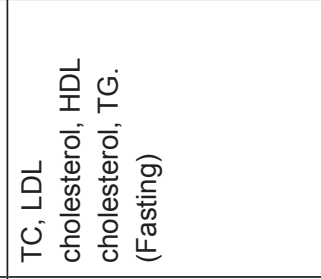 & 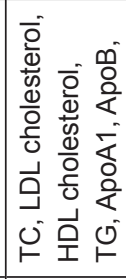 & 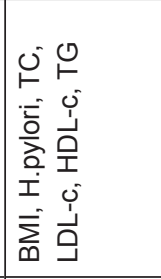 \\
\hline 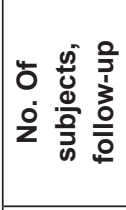 & 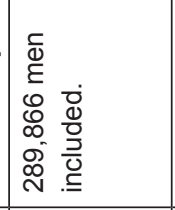 & 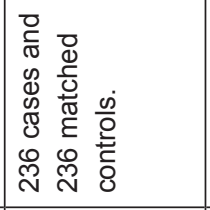 & 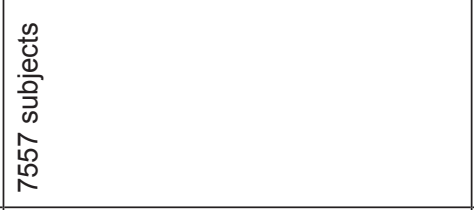 & 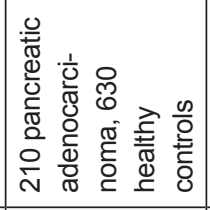 & 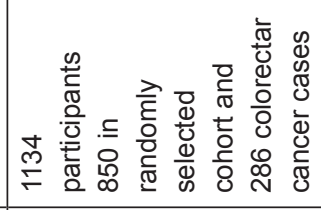 & 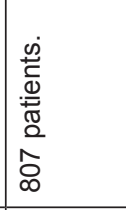 & $\begin{array}{l}\underset{\widetilde{J}}{\sigma} \\
\stackrel{+}{\leftarrow}\end{array}$ \\
\hline 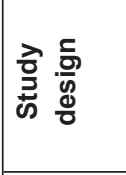 & 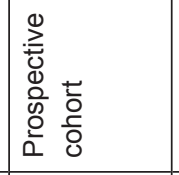 & 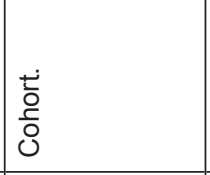 & $\begin{array}{l}t \\
0 \\
0 \\
0 \\
0 \\
\end{array}$ & 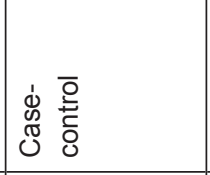 & \begin{tabular}{|l}
$t$ \\
0 \\
0 \\
0 \\
0
\end{tabular} & $\begin{array}{l} \\
0 \\
0 \\
0 \\
0\end{array}$ & $\begin{array}{l}t \\
0 \\
0 \\
0 \\
0 \\
\end{array}$ \\
\hline 중ㅎํ & \begin{tabular}{ll}
\multicolumn{1}{c}{} & \multicolumn{1}{c}{} \\
0 & \multicolumn{1}{c}{} \\
$\dot{d}$ & 0 \\
$\Sigma$ & 0 \\
\end{tabular} & 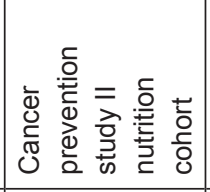 & 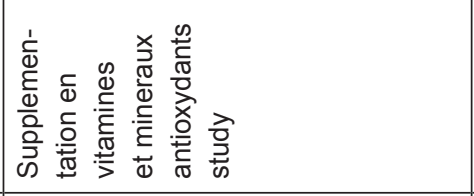 & 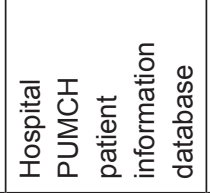 & 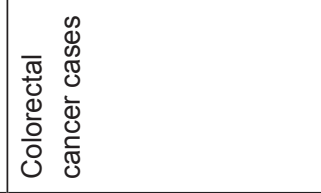 & 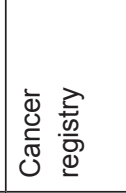 & \\
\hline 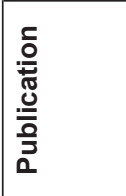 & 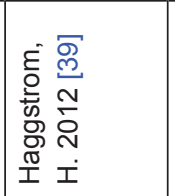 & 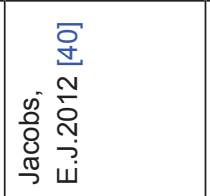 & 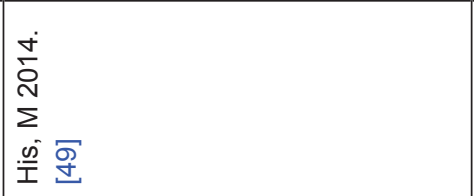 & 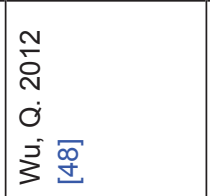 & 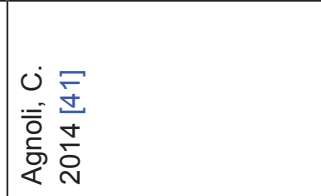 & 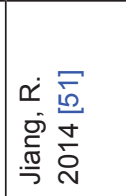 & 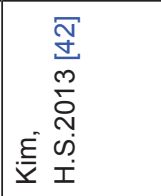 \\
\hline
\end{tabular}




\begin{tabular}{|c|c|c|c|}
\hline 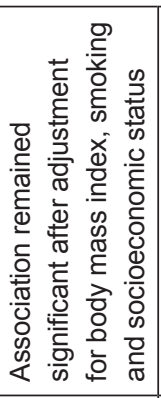 & 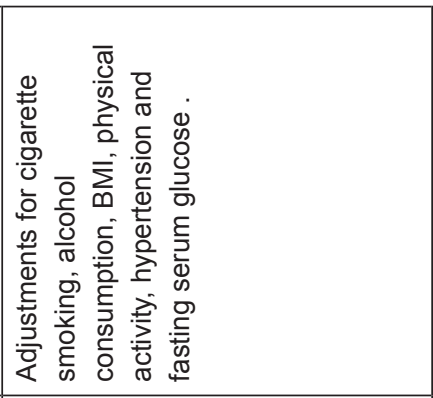 & 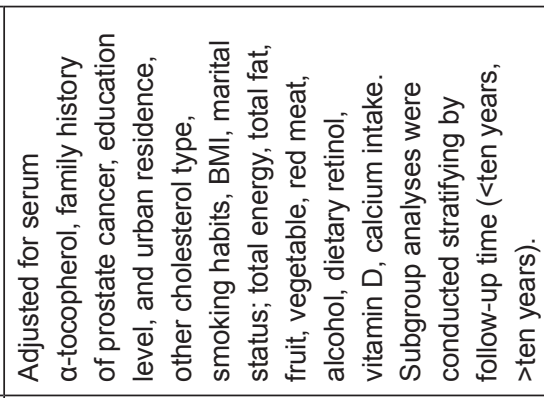 & 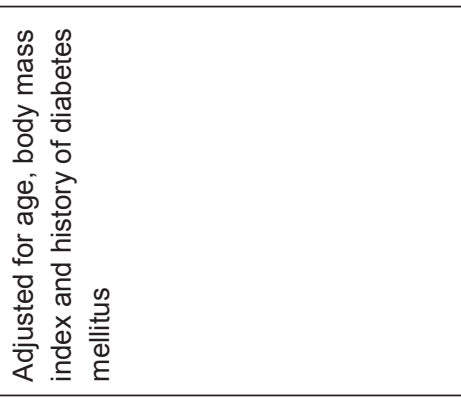 \\
\hline 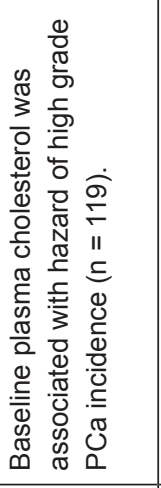 & 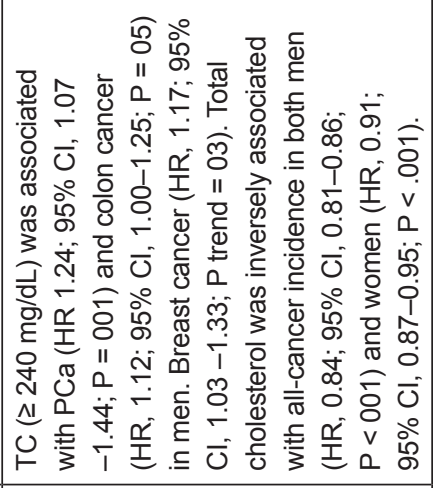 & 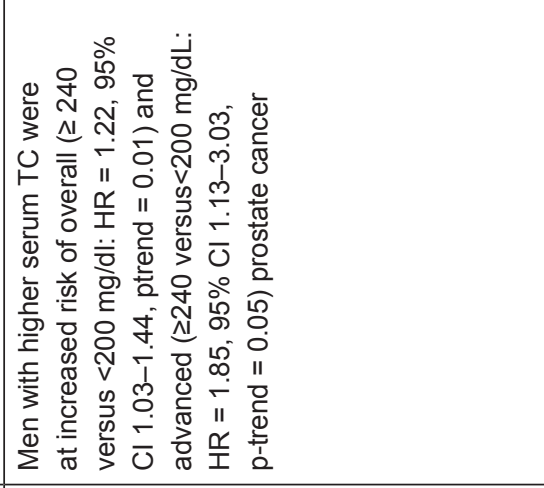 & 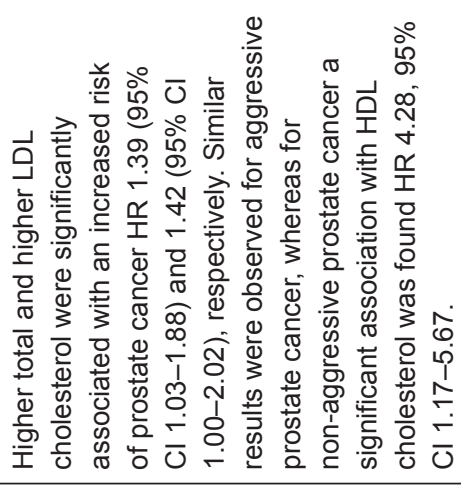 \\
\hline 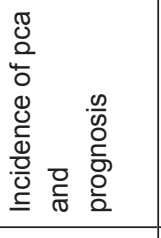 & 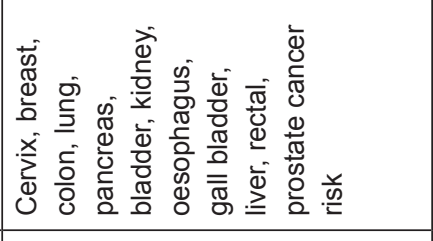 & 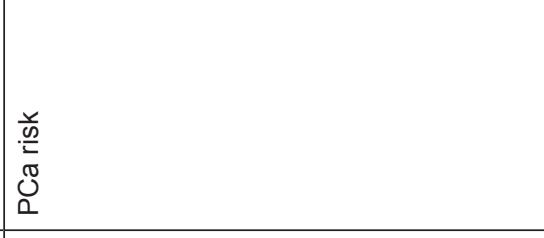 & 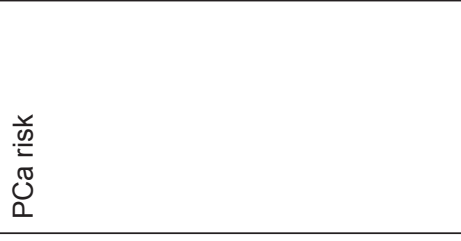 \\
\hline 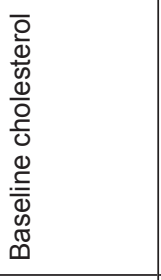 & 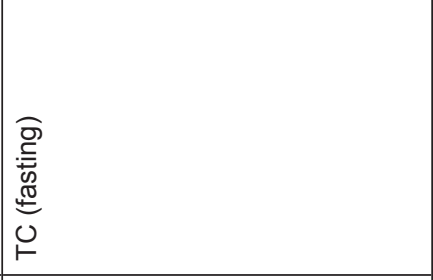 & 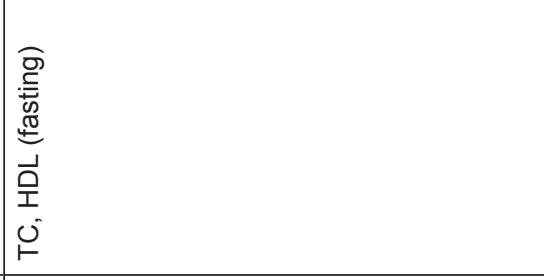 & 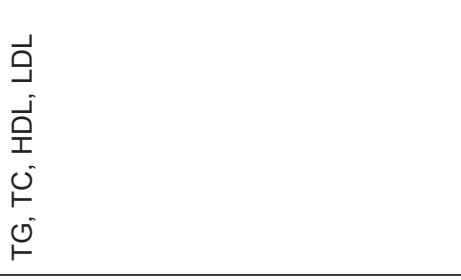 \\
\hline 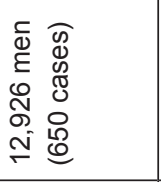 & 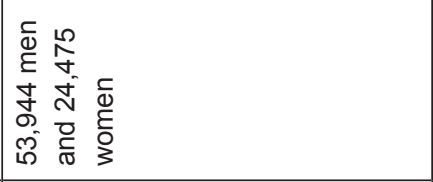 & 文 & 志 \\
\hline 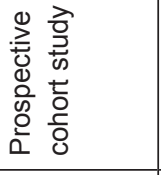 & \begin{tabular}{|l} 
\\
0 \\
0 \\
0 \\
0 \\
\end{tabular} & \begin{tabular}{|l} 
\\
0 \\
0 \\
0 \\
0 \\
0
\end{tabular} & $\begin{array}{l}\frac{t}{0} \\
\text { ํํㅇ } \\
0 \\
\end{array}$ \\
\hline 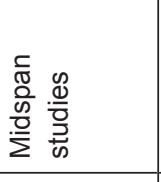 & 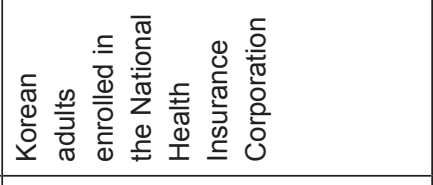 & 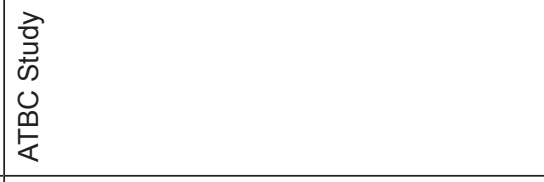 & 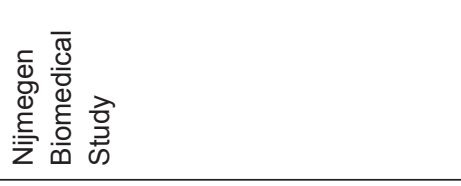 \\
\hline 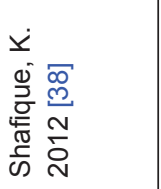 & 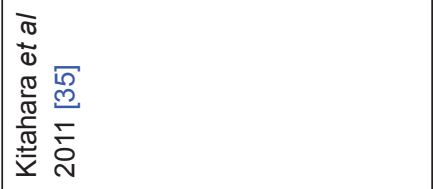 & 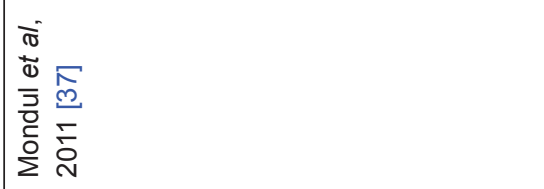 & 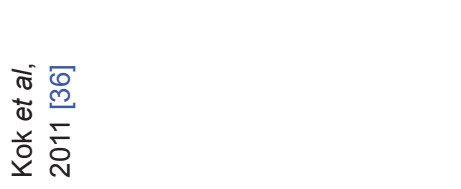 \\
\hline
\end{tabular}




\begin{tabular}{|c|c|c|c|c|c|}
\hline 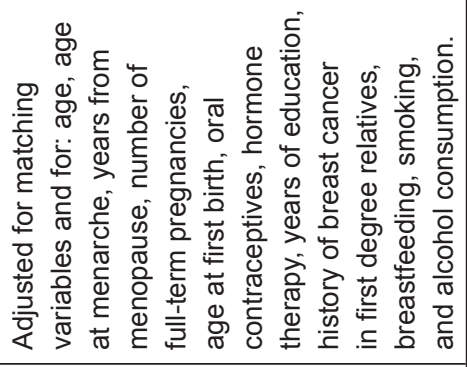 & 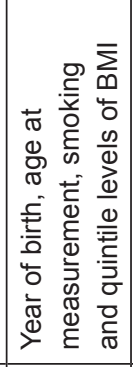 & 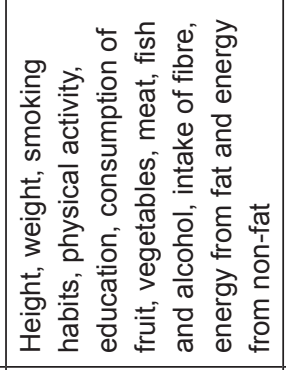 & 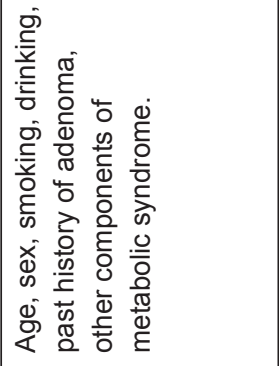 & 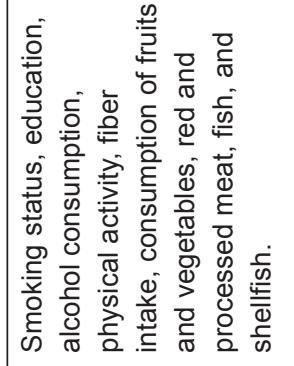 & 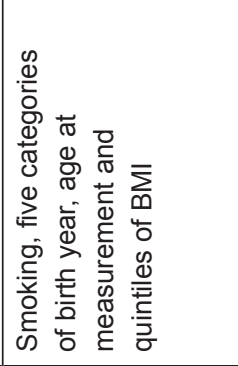 \\
\hline 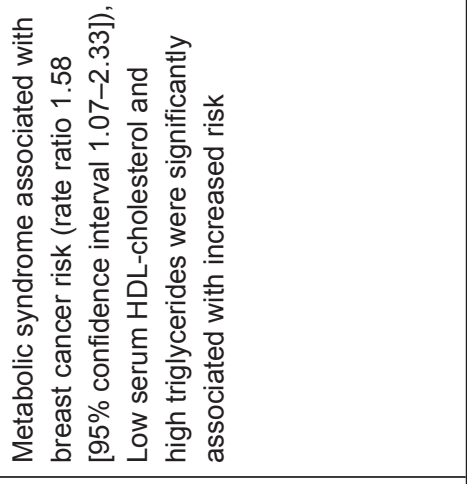 & 1 & 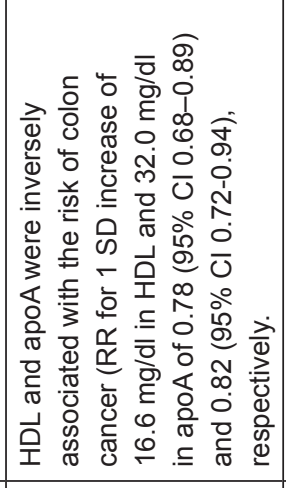 & 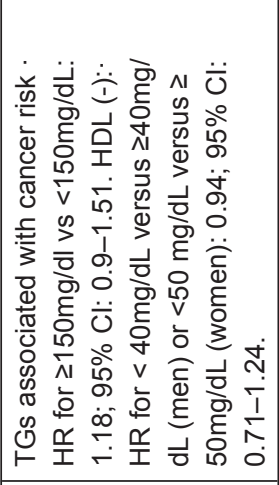 & 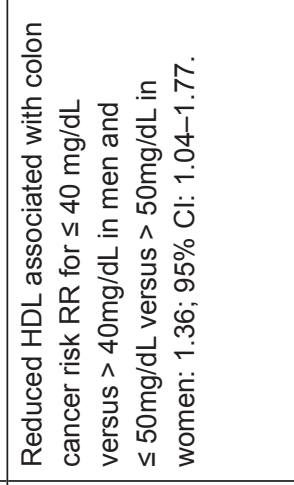 & 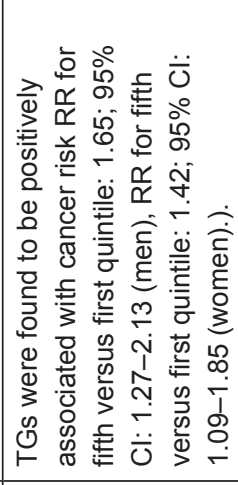 \\
\hline 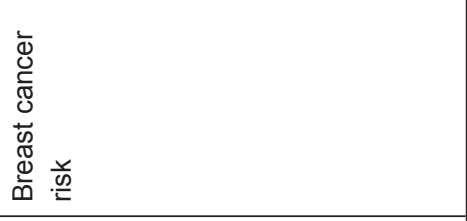 & 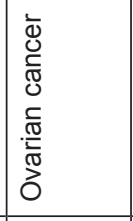 & 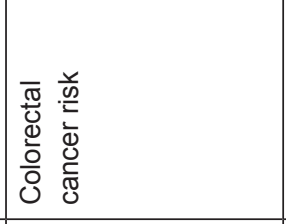 & 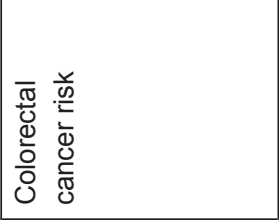 & 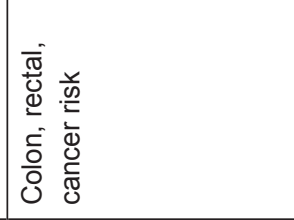 & 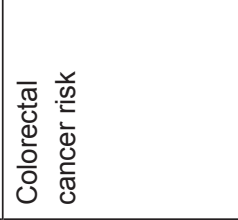 \\
\hline $\begin{array}{l}\overrightarrow{1} \\
\text { 모 } \\
0^{\circ} \\
\vdash\end{array}$ & 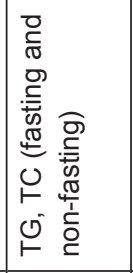 & 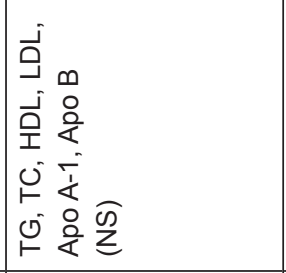 & 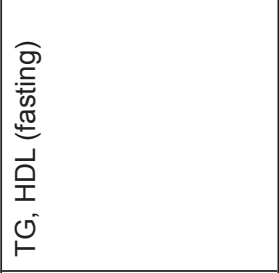 & 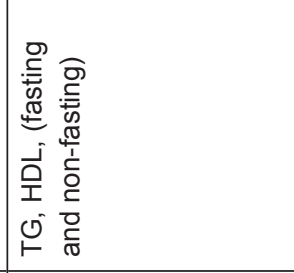 & 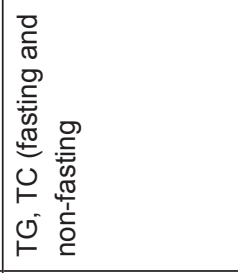 \\
\hline$\stackrel{\varnothing}{6}$ & 导 & $\stackrel{\infty}{\stackrel{\infty}{\sim}}$ & 今్ & $\begin{array}{l}\mathscr{D} \\
0 \\
0\end{array}$ & 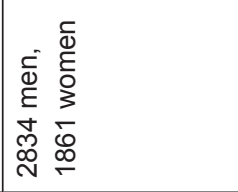 \\
\hline $\begin{array}{l}\text { t. } \\
\text { o } \\
0 \\
\end{array}$ & \begin{tabular}{|l} 
\\
0 \\
o \\
0 \\
0
\end{tabular} & 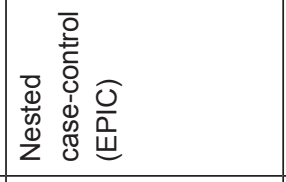 & 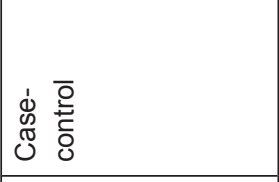 & 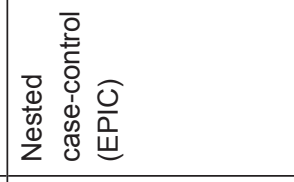 & $\begin{array}{l}\frac{t}{0} \\
\text { o } \\
0 \\
0\end{array}$ \\
\hline 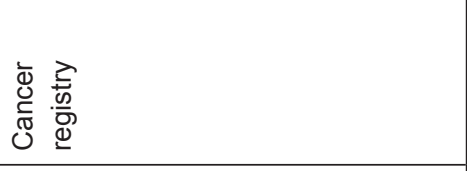 & 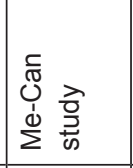 & 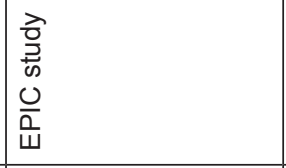 & 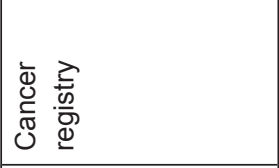 & 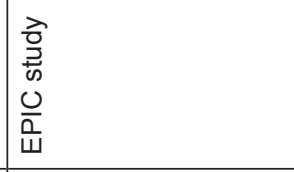 & 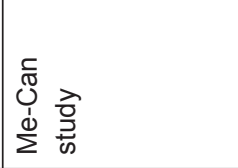 \\
\hline 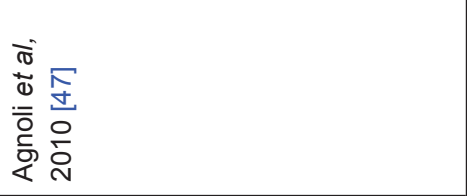 & 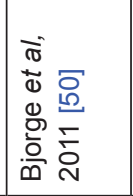 & 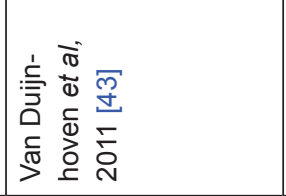 & 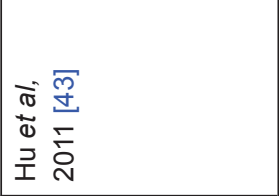 & 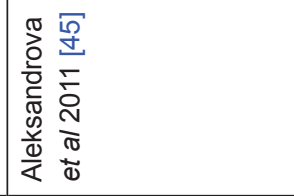 & 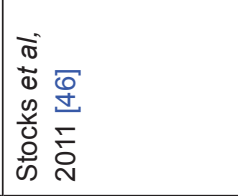 \\
\hline
\end{tabular}


suggested that insulin resistance related factors might be important for tumour progression [66]. With regards to breast cancer, two genetic variations (MNTR1a and 1b genes) have been shown to be associated both with cancer susceptibility and perturbed expression of insulin and glucose [67].

\section{Findings in AMORIS}

Apart from the interplay between glucose, triglycerides, total cholesterol, we also investigated possible associations between glucose levels and risk of breast, endometrial, and ovarian cancer in a cohort of more than 230,000 women [7, 8, 21]. Our results indicated that glucose levels below diagnostic threshold for diabetes increased the risk of endometrial and postmenopausal breast cancer. Most recently, we investigated repeated measurements of glucose, and fructosamine in relation to cancer risk and found highest cancer risks for those in the highest tertile of glucose and lowest tertile of fructosamine [16].

\section{New epidemiological findings in the literature}

The more recent literature provides further epidemiological evidence on how the glucose metabolism play a role in the risk of a number of cancers such as colon, liver, and endometrial cancers [68-72] (Table 2). Interestingly, one study on thyroid cancer found a positive association for serum glucose in men and an inverse association in women [73]. This might imply a different role of the glucose metabolism in endocrine-related cancers. However, studies on the role of serum glucose concentrations and breast cancer risk were inconclusive [74]. No new findings have been reported for the link between fructosamine and risk of cancer.

\section{Where are we today?}

Common key players in impaired glucose metabolism and cancer may indicate that both share an underlying mechanism rather than any causal role of serum glucose in carcinogenesis [75]. However, a protective effect against cancer has been suggested for metformin, one of the main medications to lower blood glucose [76-78], which supports the role of the glucose metabolism. In addition to glucose-lowering effects, metformin also possesses a direct anti-tumour effect by inhibiting protein synthesis and cell proliferation [79]. Another issue to be addressed when assessing the glucose metabolism in relation to cancer is turnover times for the serum markers. Fructosamine and $\mathrm{HbA} 1 \mathrm{c}$, which remain in the circulation for a longer duration than serum glucose, may provide more accurate representation of individual glycaemic status. The variability of serum glucose may also be accounted for by using multiple measurements as performed in one of our studies [16], either as a cumulative average or time-varying covariates [80]. Future studies should also consider the role of glucose metabolism markers in other chronic diseases, which may distort its association with cancer.

\section{Immune system}

\section{Selected biomarkers}

The role of the immune system in carcinogenesis was first shown by an observation of cancer occurring in chronic inflammation [81]. It is thought that inflammation is capable of triggering both tumour initiation and promotion through the formation of reactive oxygen species (ROS) and reactive nitrogen intermediates (RNI) [82]. C-reactive protein (CRP) is one of the most investigated markers of inflammation in the context of cancer detection and prognosis. Higher levels of post-diagnosis CRP have been linked with worse survival rates in various malignancies [83-85]. In addition to CRP, albumin, haptoglobin, and leukocytes are other commonly used markers of inflammation. Albumin is an acute-phase protein involved in blood volume regulation and transportation of molecules of low water solubility such as lipid soluble hormones and calcium. Together with leukocytes, albumin has been studied as a marker of systemic inflammation in the context of cancer survival and so far results have shown that low levels of albumin and high levels of leukocytes are associated with worse cancer prognosis [86]. Haptoglobin is a positive acute-phase protein and its plasma levels increase during inflammatory processes such as infection, extreme stress, burns, major crush injury, or allergy. The full scope of the biological function of haptoglobin is not yet defined, however 


\begin{tabular}{|c|c|c|c|c|c|c|c|}
\hline 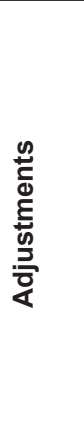 & 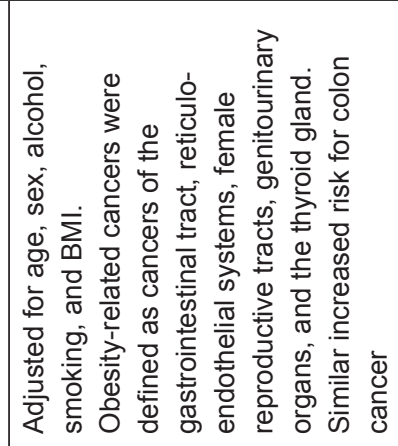 & $\begin{array}{l}0 \\
0 \\
\dot{\underline{x}} \\
\end{array}$ & 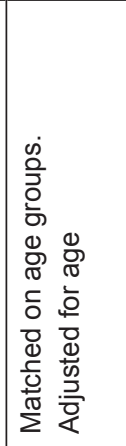 & 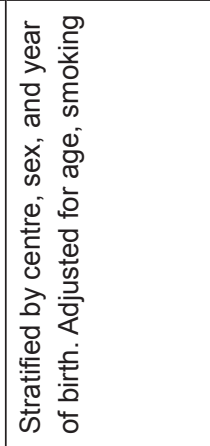 & 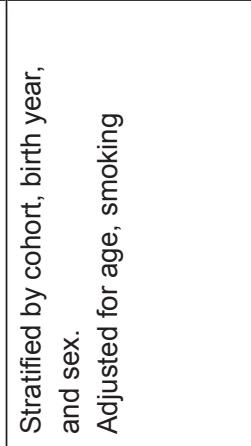 & 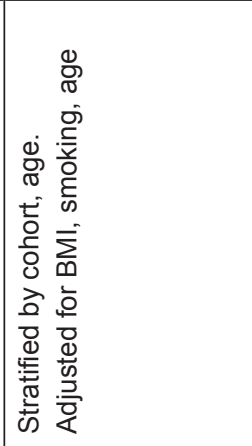 & 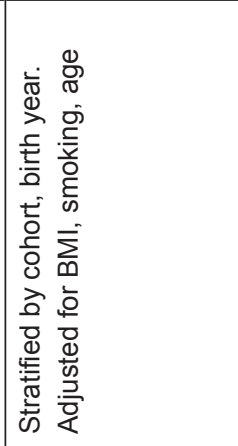 \\
\hline 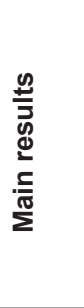 & 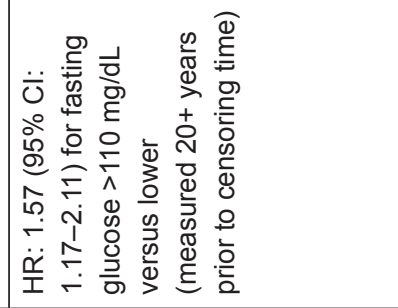 & 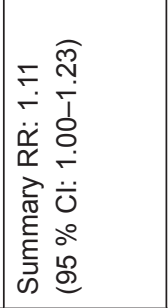 & 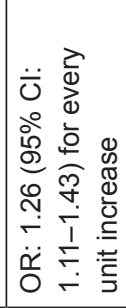 & 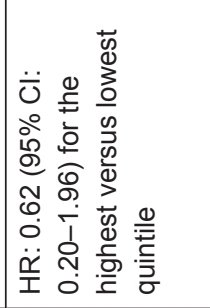 & 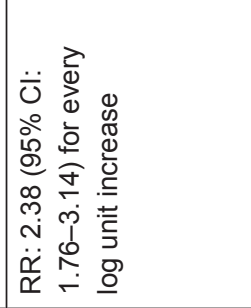 & 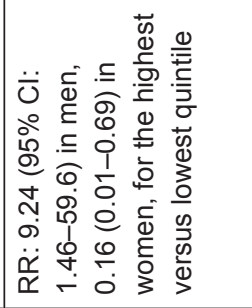 & 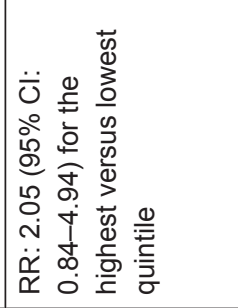 \\
\hline 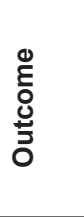 & 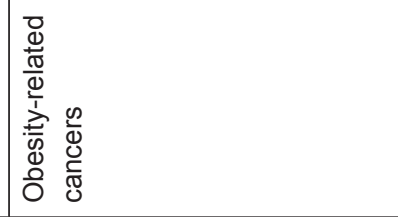 & 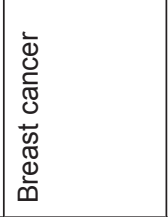 & 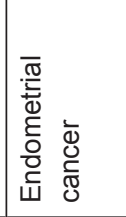 & 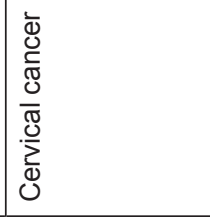 & 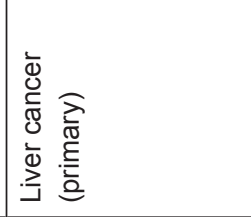 & 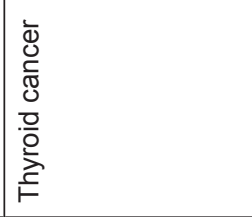 & 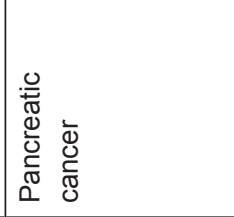 \\
\hline $\begin{array}{l}0 \\
\stackrel{0}{3} \\
0 \\
0 \\
\dot{0} \\
\text { ய. }\end{array}$ & 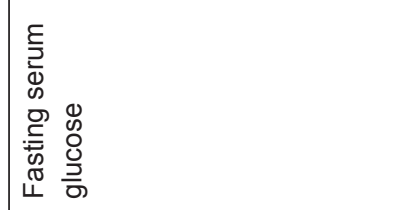 & 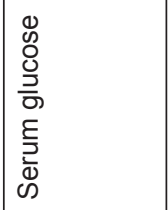 & $\begin{array}{l}0 \\
\infty \\
0 \\
0 \\
0 \\
5 \\
\frac{1}{5} \\
\frac{2}{0} \\
\infty\end{array}$ & 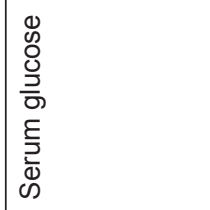 & 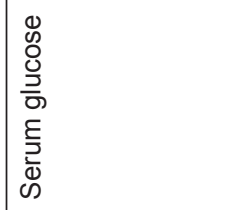 & 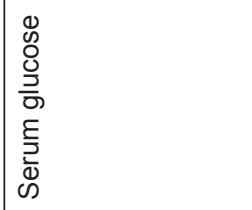 & 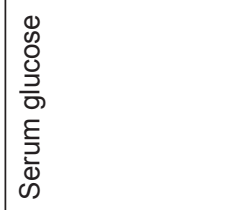 \\
\hline 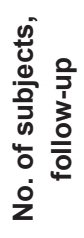 & 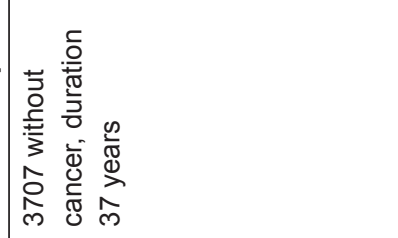 & 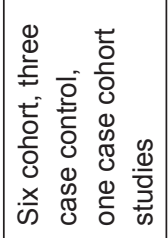 & 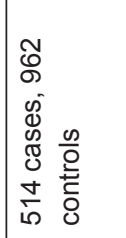 & 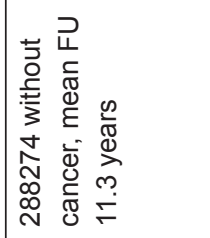 & 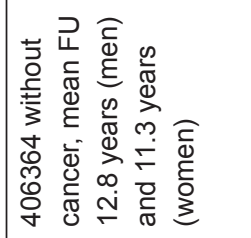 & 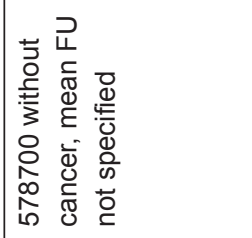 & 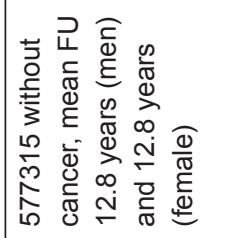 \\
\hline 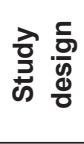 & $\begin{array}{l} \\
\text { t} \\
\overline{0} \\
0 \\
0\end{array}$ & 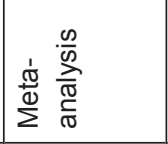 & 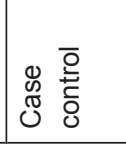 & $\begin{array}{l}t \\
\overline{0} \\
\overline{0} \\
0 \\
0\end{array}$ & $\begin{array}{l}\frac{t}{0} \\
\frac{5}{0} \\
0\end{array}$ & 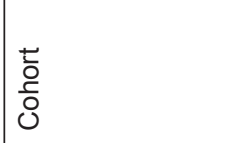 & $\begin{array}{l}\frac{t}{0} \\
\frac{\bar{g}}{0} \\
0\end{array}$ \\
\hline 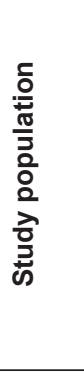 & 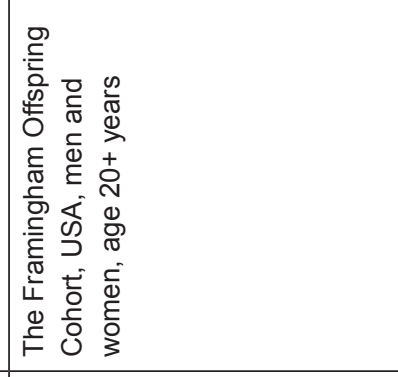 & 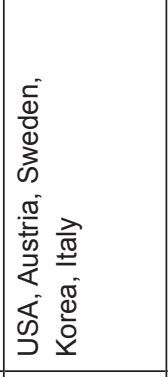 & 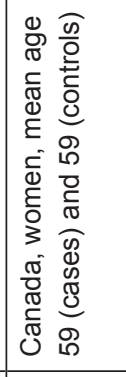 & 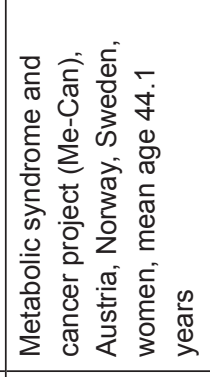 & 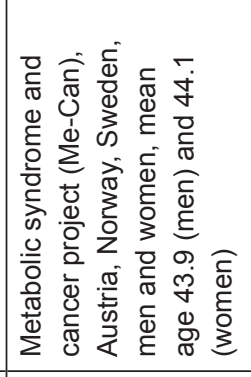 & 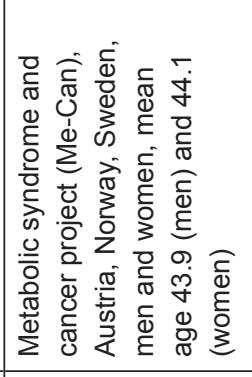 & 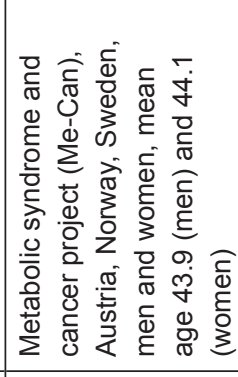 \\
\hline 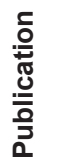 & 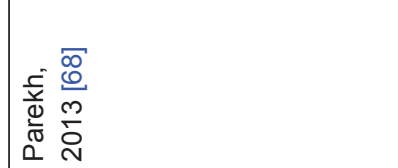 & 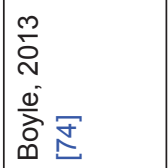 & 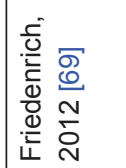 & 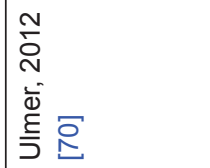 & 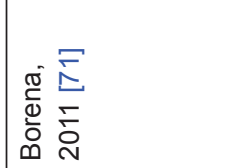 & 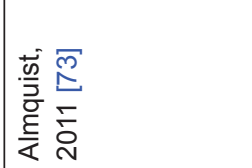 & 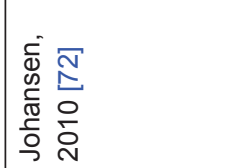 \\
\hline
\end{tabular}


experimental studies have hypothesised that haptoglobin polymorphisms may contribute to increased oxidative stress and low-grade chronic inflammation [87, 88]. There is also observational evidence indicating that allergy (measured by Immunoglobulin E (IgE)), which is highly linked to inflammation, is associated with higher risk of solid tumours such as breast, prostate, and colorectum [9].

\section{Findings in AMORIS}

We have studied different immunological markers in relation to cancer risk [9, 13, 22]. One study was of particular interest, because it replicated the findings for one measurement of CRP and leukocytes with three repeated measurements [13]. When looking into specific major cancers including prostate, breast, lung, gastrointestinal, bladder, cervix. and skin cancer, a positive association was only seen for lung cancer. The lack of association between inflammatory markers and specific cancer risk was further shown when we investigated serum CRP, leukocytes, albumin, and haptoglobin in relation to prostate cancer [22]. We also assessed the association between total serum levels of $\operatorname{lgE}$ and cancer risk in 24,820 persons and found a weak inverse association between quartiles of IgE and cancer risk [9].

\section{New epidemiological findings in the literature}

A consistent association between serum CRP and cancer risk is corroborated by more recent findings (Table 3), as shown by a metaanalysis of 11 studies in Western populations showing an increased cancer risk for higher levels of CRP [89]. Similar findings were reported in Asian populations [90]. Results for specific cancers remain conflicting except for lung cancer, where a positive association with CRP and leukocytes has been reported. This is consistent with our findings seen in the AMORIS database [89, 91, 92]. Some evidence, although weaker, has been reported for colorectal, breast, ovarian. and liver cancer [93-97], whereas no association has been found for prostate and pancreatic cancers [98-100]. Regarding serum lgE, most observational studies confirmed an inverse association with risk of developing brain cancer, particularly glioma [101-104]. To date, little evidence exists for association with any other cancers.

\section{Where are we today?}

Although biological studies consistently link inflammation to carcinogenesis [105], the role of common serum inflammatory markers in predicting cancer risk still remains unclear. This may be partly because of the wide spectrum of inflammation, which is also an essential part of many pathologic conditions such as cancer and cardiovascular disease. The non-specificity of such cancer markers may explain the lack of associations found in observational studies, urging future studies to deploy novel methods to increase sensitivity of cancer prediction using these markers. Another possible explanation is the genetic variation of these markers, instead of their quantitative protein expression, that influences cancer development. This is supported by two recent studies suggesting different risk of colorectal cancer conferred by CRP polymorphisms [106, 107]. Additionally, these markers are usually analysed separately and a combined analysis may provide a better approximation with respect to early cancer detection, as it has shown in the case when combining scores of CRP with IL-8 [108] or haptoglobin with serum amyloid A (SAA) [109] in predicting lung cancer risk, and the ratio of reactive oxygen metabolites and CRP for colorectal cancer [110].

\section{Liver metabolism}

\section{Selected biomarkers}

Gamma-glutamyl transferase (GGT), is a central enzyme in the glutathione (GSH) metabolism, a ubiquitous antioxidant thiol, and plays an important role in maintaining tissue oxidant/antioxidant balance, cellular defence, proliferation, and protection against further oxidative stress [111]. The latter may explain its potential role in carcinogenesis, in addition to its links with type 2 diabetes, cardiovascular, and chronic kidney disease [112-115]. Elevated levels of GGT have been associated with poorer endometrial cancer prognosis, increased risk of progression of high-grade cervical dysplasia to invasive carcinoma [116], increased risk of breast cancer amongst premenopausal women [117], increased risk of cancer in men [118], increased risk of liver cancer [119] and it has been reported to play an independent role in the prediction of overall survival (OS) in metastatic colorectal carcinoma [120]. 


\begin{tabular}{|c|c|c|c|c|c|c|c|c|}
\hline 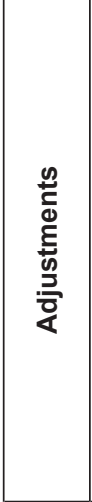 & 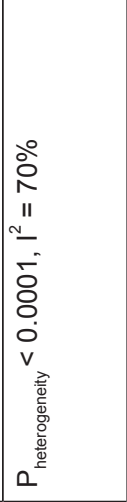 & 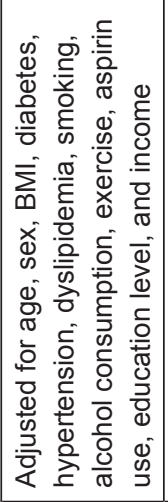 & 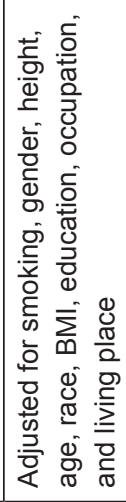 & 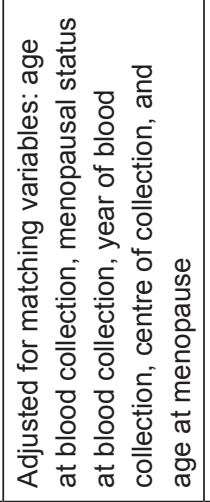 & 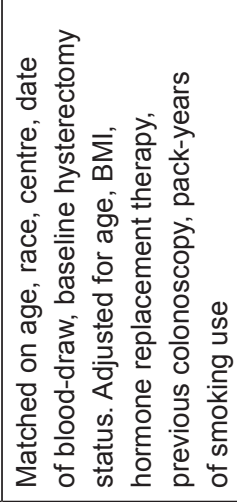 & 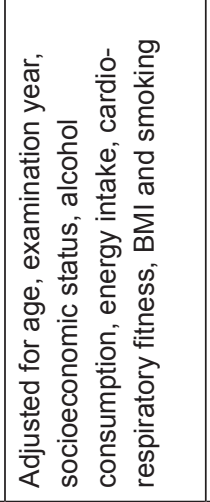 & 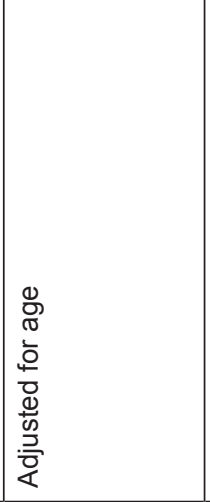 & 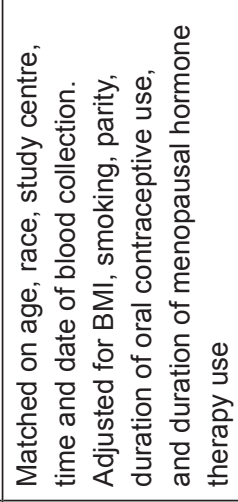 \\
\hline 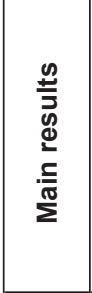 & 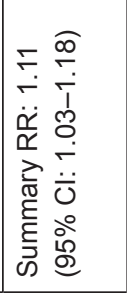 & 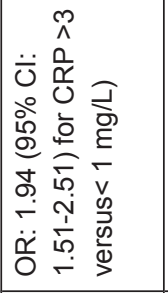 & 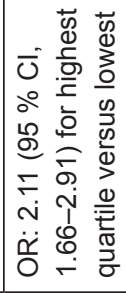 & 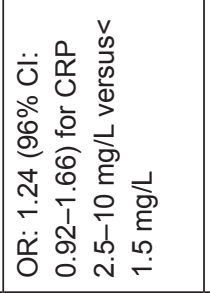 & 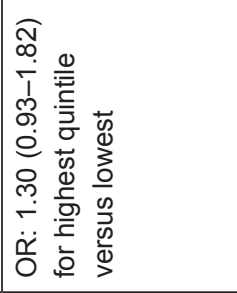 & 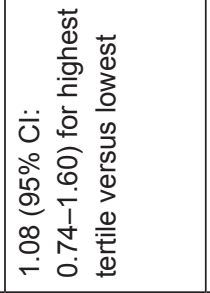 & 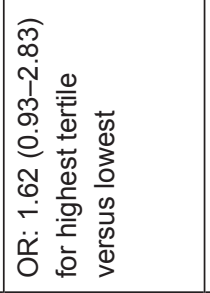 & 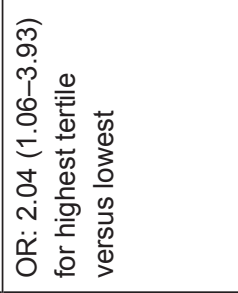 \\
\hline 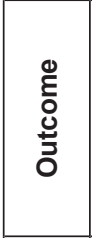 & 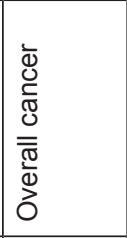 & 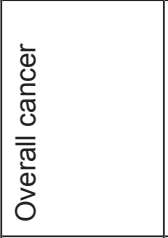 & 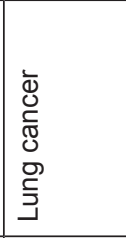 & 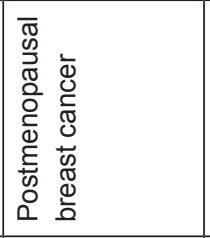 & 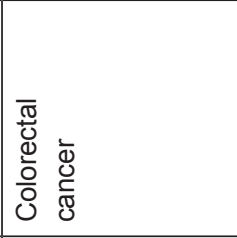 & 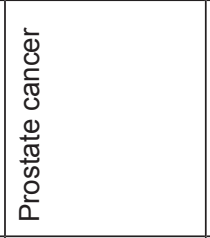 & 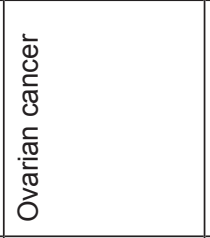 & 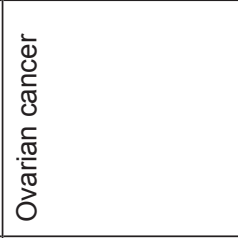 \\
\hline 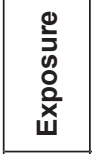 & $\begin{array}{l}\frac{\partial}{y} \\
0\end{array}$ & $\frac{a}{\frac{\gamma}{0}}$ & $\begin{array}{l}\frac{\partial}{y} \\
0\end{array}$ & $\frac{a}{\frac{N}{v}}$ & $\frac{\partial}{\frac{p}{0}}$ & $\begin{array}{l}0 \\
\frac{y}{v} \\
0\end{array}$ & $\begin{array}{l}\frac{\partial}{y} \\
0\end{array}$ & $\begin{array}{l}\frac{a}{v} \\
0\end{array}$ \\
\hline 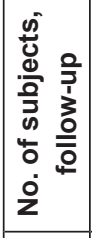 & 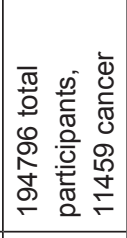 & 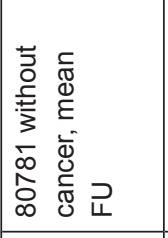 & 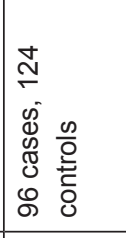 & 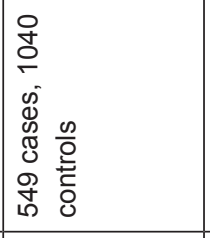 & 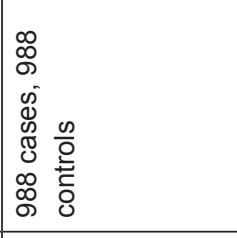 & 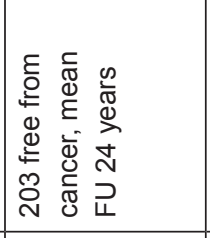 & 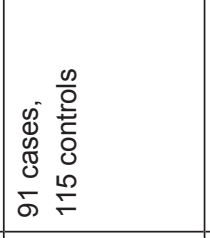 & 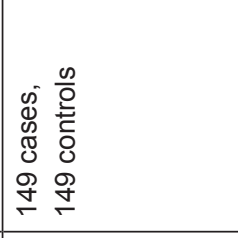 \\
\hline 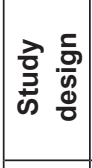 & 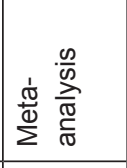 & 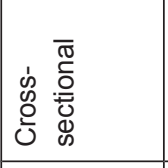 & 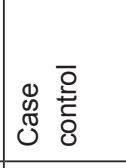 & 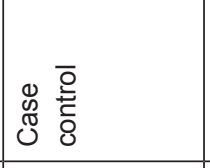 & 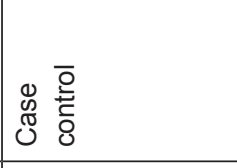 & \begin{tabular}{|l|} 
\\
0 \\
0 \\
0 \\
0 \\
\end{tabular} & 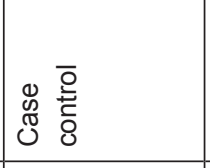 & 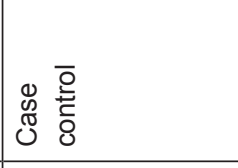 \\
\hline 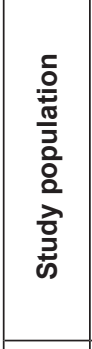 & 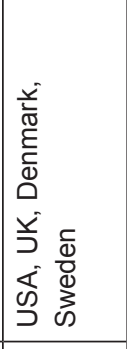 & 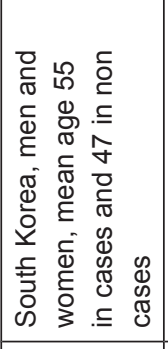 & 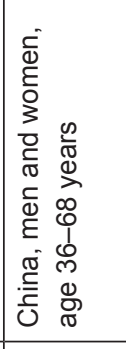 & 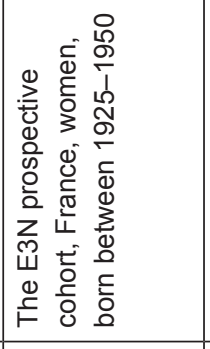 & 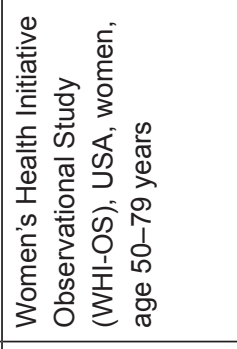 & 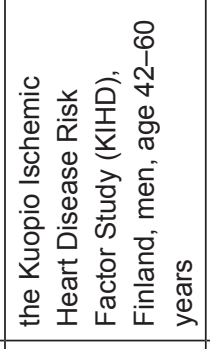 & 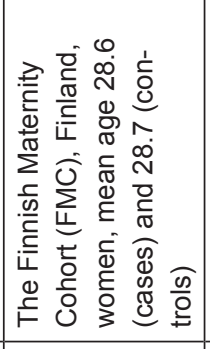 & 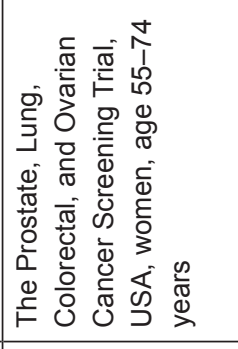 \\
\hline 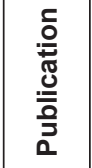 & 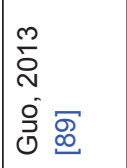 & 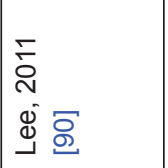 & 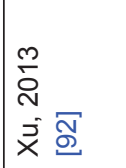 & 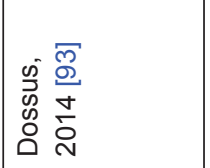 & 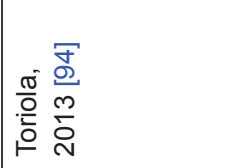 & 定 & 웅 & 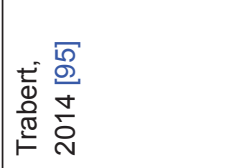 \\
\hline
\end{tabular}




\begin{tabular}{|c|c|c|c|c|c|c|}
\hline 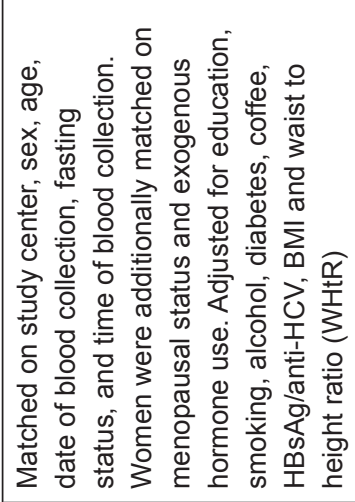 & 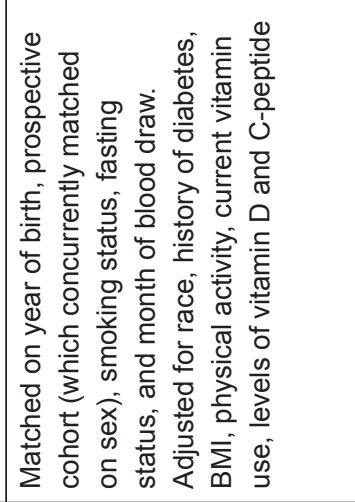 & 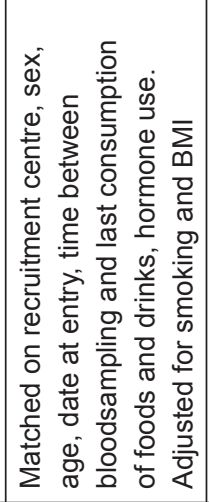 & 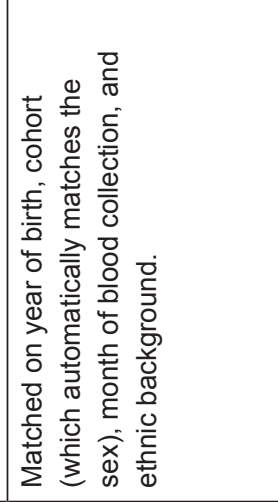 & 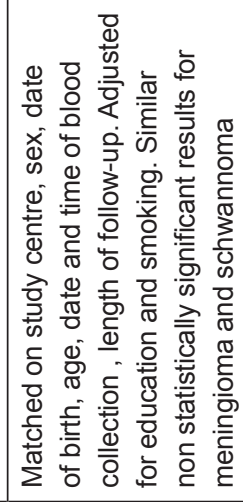 & 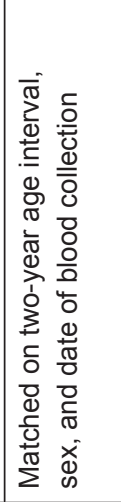 & 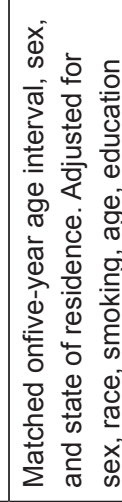 \\
\hline 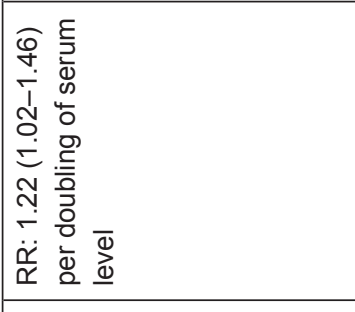 & 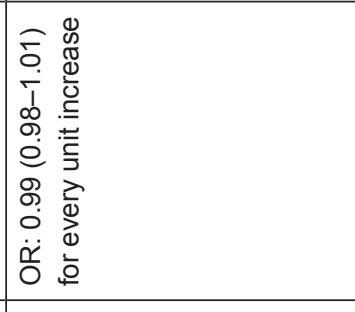 & 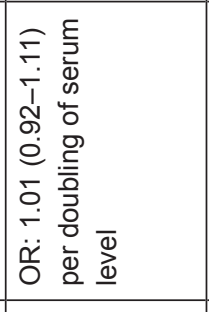 & 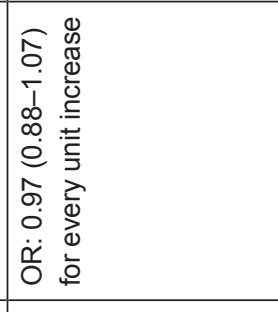 & 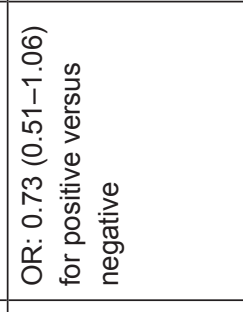 & 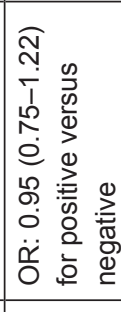 & 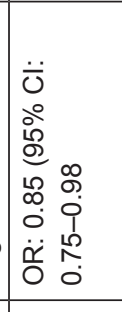 \\
\hline 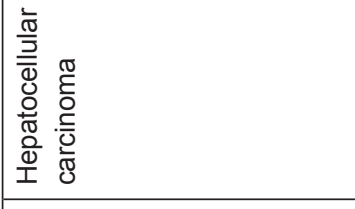 & 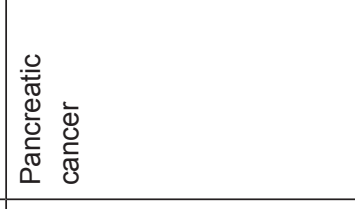 & 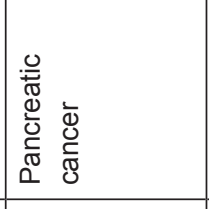 & 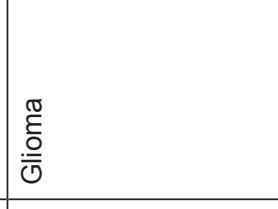 & \begin{tabular}{|l|}
$\underline{\sigma}$ \\
$\frac{\tilde{\sigma}}{\bar{\sigma}}$ \\
$\overline{0}$
\end{tabular} & 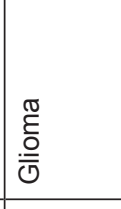 & 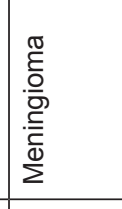 \\
\hline 竞 & 竞 & 总 & 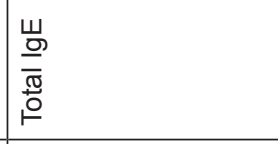 & 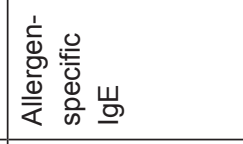 & 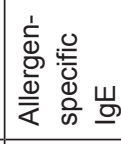 & \begin{tabular}{|l} 
岁 \\
$\frac{0}{\bar{\sigma}}$ \\
$\stackrel{0}{\circ}$
\end{tabular} \\
\hline 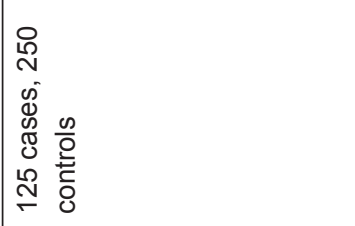 & 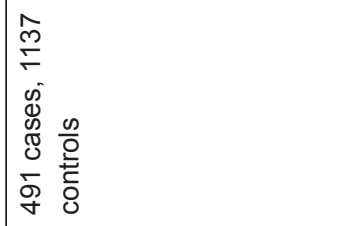 & 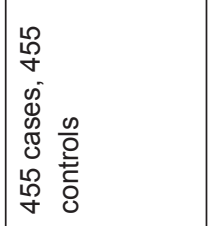 & 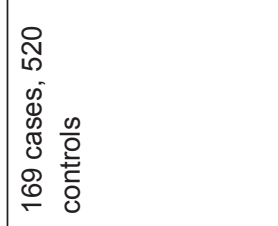 & 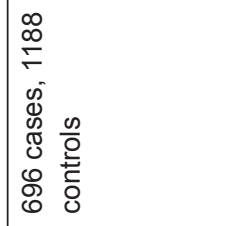 & 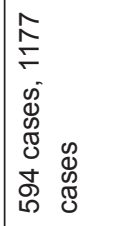 & 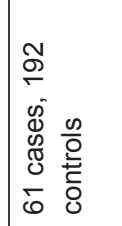 \\
\hline 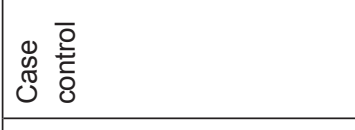 & 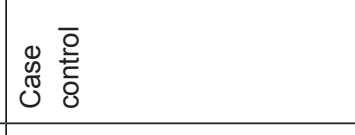 & 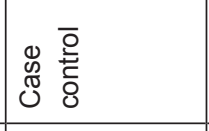 & 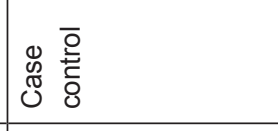 & 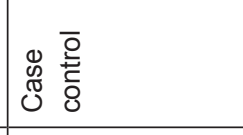 & 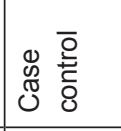 & 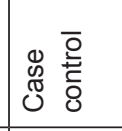 \\
\hline 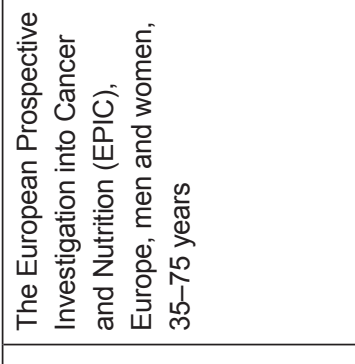 & 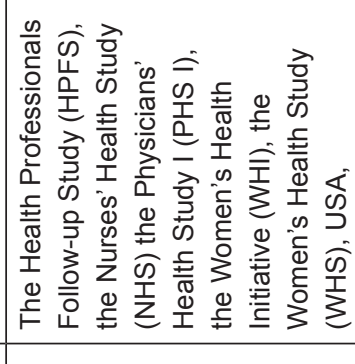 & 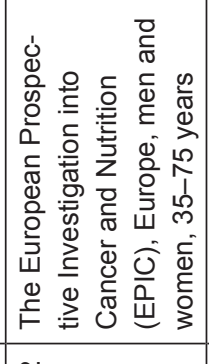 & 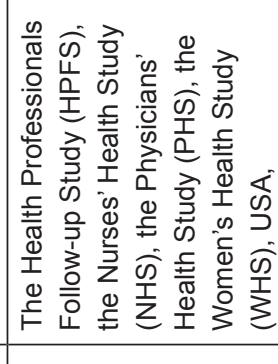 & 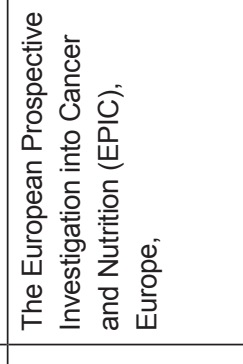 & 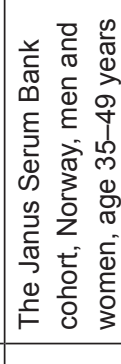 & 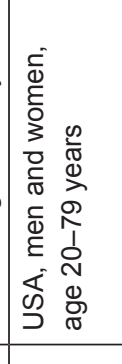 \\
\hline 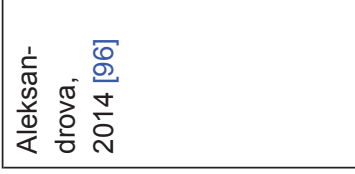 & 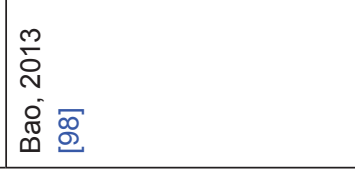 & 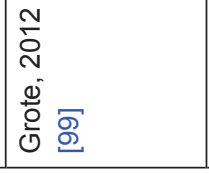 & 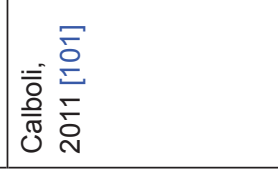 & 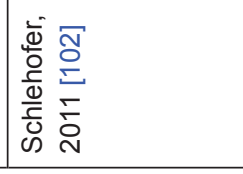 & 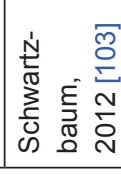 & 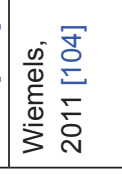 \\
\hline
\end{tabular}




\section{Findings in AMORIS}

We have investigated GGT serum levels in relation to cancer risk in 545,460 persons and found evidence of associations between elevated GGT and risk of developing different cancers. The strength of this association varied by levels of glucose which may suggest that hyperglycaemia can result in oxidative stress which in turn initiate damaging pathways of carcinogenesis [19].

\section{New epidemiological findings in the literature}

Since the last AMORIS publication, several studies have analysed the association between GGT and cancer risk and prognosis [121-128] (Table 4). All studies are in agreement with our findings in AMORIS and show that high levels of GGT are an indicator of elevated cancer risk and poor disease prognosis. Three studies showed that high pre-therapeutic levels of GGT are associated with advanced tumour stage and serve as an independent prognostic marker of poor prognosis in gynaecological cancers [122, 125, 126]. A case-cohort study in Taiwanese men showed that high levels of GGT were associated with risk of all-cause death, all cancer, and hepatocellular carcinoma (HCC) mortality [124]. Furthermore, another study analysing GGT and HCC prognosis showed that high levels of pre-treatment GGT were associated with reduced OS rates, when compared to those with normal pre-treatment GGT levels [121]. In addition, elevation of serum GGT levels was found to be an indicator of aggressive intrahepatic cholangiocarcinoma behaviours and a predictor of poor clinical outcomes [127]. Interestingly, one study in Japanese adults found that GGT was only a predictor of cancer risk for alcohol-related cancers in current drinkers [123]. GGT has also been reported to play an independent role in the prediction of OS in metastatic colorectal carcinoma [120].

Finally, a meta-analysis by Long et al concluded that GGT predicts cardiovascular and cancer mortality [129], whereas Kunustor et al in their meta-analyses showed that baseline levels of GGT are positive independent predictors of overall cancer risk as well as for all-cause mortality $[130,131]$.

\section{Where are we today?}

Overall epidemiological evidence shows that high levels of GGT are associated with cancer risk and many experimental studies have intended to explain this link suggesting different biological mechanisms [132-136]. These pathways have been demonstrated for cancer specific sites which may be explained by the high variability present in cancer cells together with the effect of other factors, such as environment, drugs, and diet that could modify cancer cells phenotype including GGT expression [137].

\section{Iron metabolism}

\section{Selected biomarkers}

The iron metabolism is another pathway potentially linked with carcinogenesis. Iron plays a fundamental role in important biological processes in eukaryotic cells such as oxygen transport, cellular respiration, and redox reactions; consequently iron homeostasis is precisely regulated. Most circulating iron is bound to transferrin; the rest of iron is either serum-free iron or iron stored in cells bound to ferritin. Total iron-binding capacity (TIBC) measures the ability of plasma proteins to bind iron and reflects the fraction of transferring- free places to bound iron, meaning that low values of TIBC evidence transferrin saturation (TSAT) and consequently high iron stores in cells.

Different mechanisms of iron involvement in carcinogenesis have been suggested, including oxidative DNA damage by iron-catalysed free radical production, alterations in gene expression consistent with increased iron requirements in proliferating cells, as well as decreased immune surveillance against cancer [138]. Excess iron has been shown to promote protein and genomic alterations mirrored in human cancers [139] and this may occur via iron-induced persistent oxidative stress [139]. Moreover, iron sequestration machinery is activated by inflammatory processes associated with chronic diseases such as breast cancer for which cancer-associated anaemia is being broadly studied [140]. 


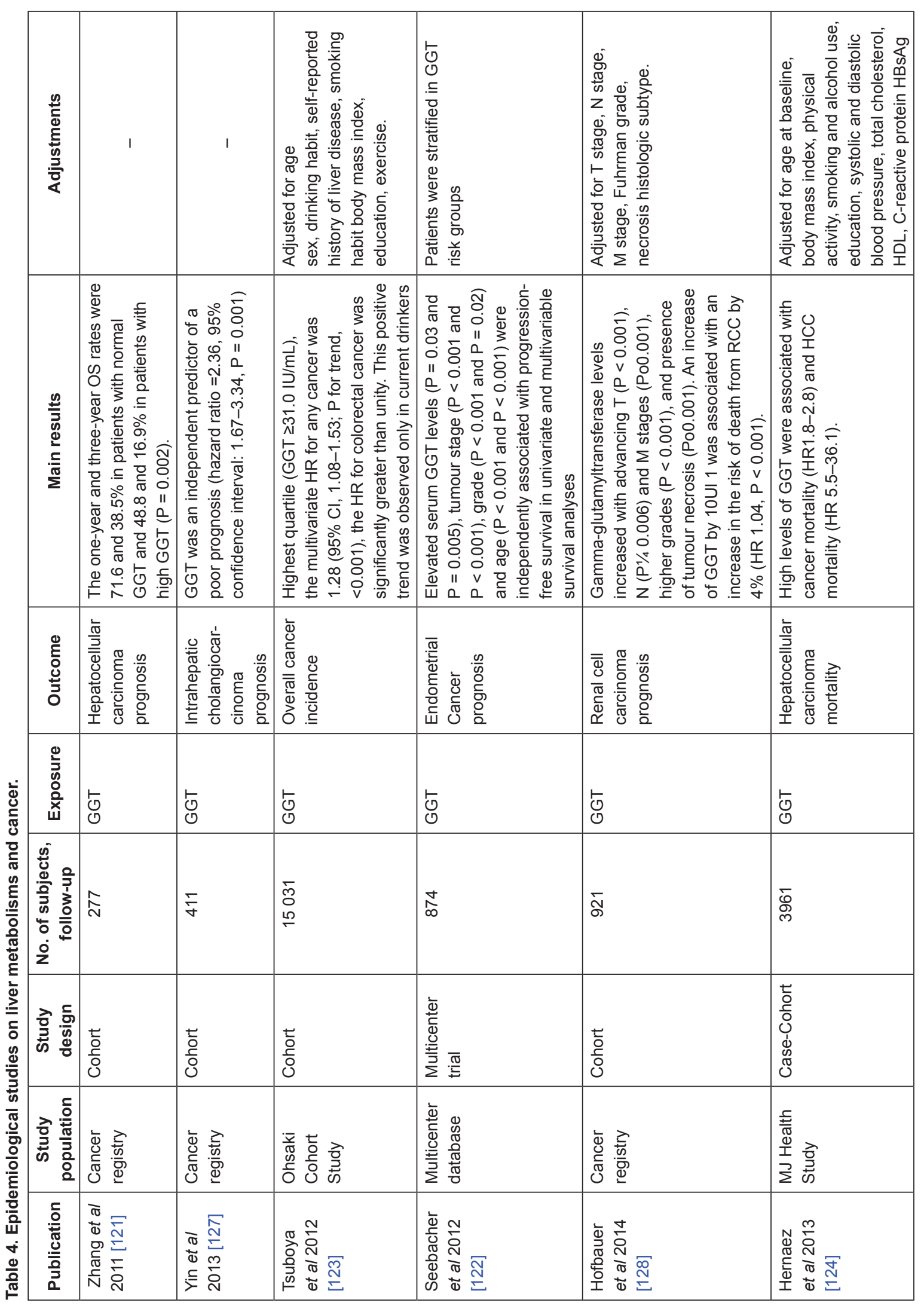




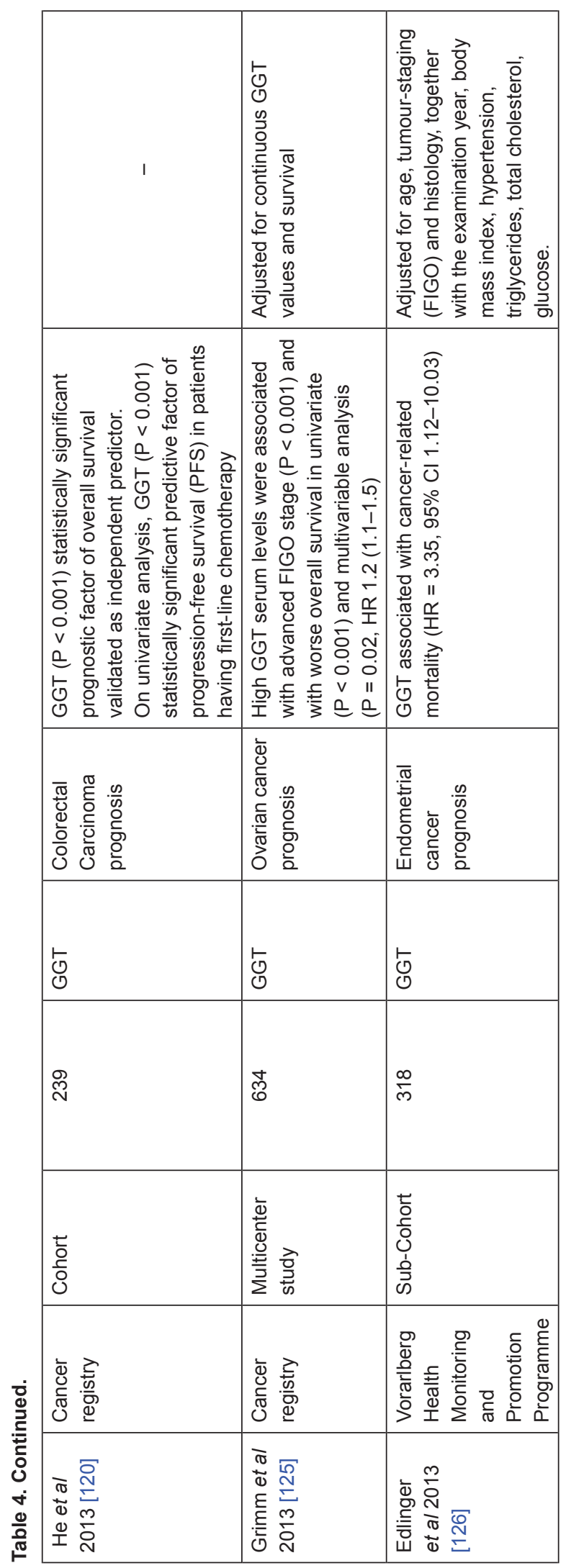




\section{Findings in AMORIS}

Using a cohort of 220,642 participants with baseline measurements of serum iron, TIBC, and CRP, we found a positive association between TIBC (i.e. low TSAT) and the risk of overall and in particular colon cancer [5]. Serum iron, on the other hand, did not correlate with overall cancer risk, although a positive association with postmenopausal breast cancer was shown. These observations thus support a role of iron metabolism in relation to specific cancer risk.

\section{New epidemiological findings in the literature}

Only one recently published study focused on serum iron as a marker of the iron metabolism in the context of cancer risk. This cohort study of 309,443 men and women in Taiwan reported an increased risk of cancer in individuals with high serum iron [141]. Specific cancer analysis showed an increased risk of breast cancer for serum iron $\geq 140 \mu \mathrm{g} / \mathrm{dL}$-hazard ratio (HR): $1.3195 \%$, confidence interval (Cl): 1.01-1.70 - compared to lower levels, which is similar to our findings for postmenopausal breast cancer. Other recent studies measured iron based on dietary intake subclassified as dietary heme iron, supplemental iron, and dietary intake of meat [142-145]. Dietary iron was assessed mainly using food frequency questionnaires and heme iron intake was usually determined indirectly by calculating a type-specific percentage of the total iron content in meat [144, 145]. Furthermore, a broad meta-analysis examining different cancer types in association with serum iron markers and dietary iron markers, found a negative association between cancer risk and levels of iron storage biomarkers, mostly with serum ferritin. Moreover, authors reported that a higher intake of heme iron showed a tendency towards a positive association with cancer risk [146]. Similar conclusions for dietary markers were obtained in a colorectal cancer meta-analysis, suggesting a significant positive association of heme iron intake and risk of colorectal cancer [147].

\section{Where are we today?}

Iron homeostasis is closely linked to anaemia, which impairs many physiological processes [148]. Considering the association between anaemia and mortality [149], it is possible that the positive association between serum iron and risk of cancer emerges as a consequence of other fatal diseases in persons with low levels of iron, thus removing them from the population at risk of developing cancer. Future research should address risks associated with different types of anaemia in addition to serum components of iron metabolism when assessing their link to cancer susceptibility.

\section{Bone metabolism}

\section{Selected biomarkers}

Components of bone metabolism have been indicated to be involved in carcinogenesis. Since calcium homeostasis is mainly influenced by vitamin $D$ and parathyroid hormone instead of dietary calcium [150], the use of serum calcium could be useful in investigating the aetiology of cancer. lonised serum calcium level is a direct measure of the amount of metabolically active serum calcium but is not routinely measured [151]. Correction of total calcium levels based on serum albumin is therefore used to obtain an estimate of the free ionised calcium level, since almost half of serum calcium is in protein-bound form and alteration of serum albumin may affect levels of free ionised calcium $[150,151]$. Inorganic phosphate $(\mathrm{Pi})$ is another dietary constituent well-known for its role in skeletal mineralisation, and normal levels of $\mathrm{Pi}$ are essential to maintain normal cellular function [152]. As a result, it has been suggested that Pi may act as an active regulator of growth rather than a merely compulsory element in cellular homeostasis. A particular link between calcium and gastrointestinal cancer has been suggested, since dietary calcium may activate calcium receptor and bind bile acids in gastrointestinal tract, in addition to the role of serum calcium in cellular metabolism [153, 154]. Recent studies also indicated that inorganic phosphate might be implicated in carcinogenesis, as high-inorganic phosphate diet has been linked to an increased development of lung and skin cancers [155, 156]. Abnormal levels of inorganic phosphate are thought to affect carcinogenesis by amplification of Akt signalling and 5' cap eukaryotic dependent translation [157, 158]. 


\section{Findings in AMORIS}

We investigated serum calcium in relation to risk of prostate and gastrointestinal cancer, and serum inorganic phosphate in relation to risk of overall and site-specific cancers $[5,17,18,20]$. We found a weak negative association between calcium and prostate cancer, which was likely explained by a strong association between calcium and all-cause mortality. For gastrointestinal cancer, higher risks of oesophageal and colorectal cancer were linked to higher levels of albumin-corrected calcium in women, indicating the importance of calcium correction based on albumin levels. In men, a similar but weaker association was found. The study focusing on inorganic phosphate showed a positive association with risk of overall cancer in men, but an inverse association in women.

\section{New epidemiological findings in the literature}

In support of the above findings, another Swedish-based study showed a positive trend between levels of albumin-adjusted calcium and risk of prostate cancer in men [159] (Table 5). Similar findings with total and ionised serum calcium were reported when prostate cancer death was used as a surrogate outcome [160]. Nonetheless, an inverse association was observed in an Asian study [161]. No new studies have been published investigating the association between serum inorganic phosphate and risk of cancer.

\section{Where are we today?}

In clinical studies, the potential chemopreventive effects of calcium in cancer, particularly colorectal cancer, remain conflicting [162]. A recent dose-response meta-analysis showed an inverse association between dietary calcium, calcium supplementation, and risk of colorectal cancer [163]. However, the role of serum levels of calcium as well as its counterpart, serum inorganic phosphate, in relation to cancer prediction remains elusive. As bone metabolism is tightly regulated, abnormalities in calcium and phosphate levels may reflect a defect in bone regulation instead of dietary intake. Further clinical and observational studies exploring the potential roles of calcium and phosphate in cancer should take into account their regulators such as vitamin D, parathyroid hormone, and fibroblast growth factor 23 (FGF-23) [164, 165] in order to fully comprehend how they are involved in carcinogenesis.

Table 5. Epidemiological studies on bone metabolism and cancer.

\begin{tabular}{|l|l|l|l|l|l|l|l|}
\hline Publication & Study population & Study design & $\begin{array}{l}\text { No. of subjects, } \\
\text { follow-up }\end{array}$ & Exposure & Outcome & Main results & Adjustments \\
\hline $\begin{array}{l}\text { Brandstedt, } \\
\text { 2012 [159] }\end{array}$ & $\begin{array}{l}\text { The Malmo Diet } \\
\text { and Cancer Study } \\
\text { cohort, Sweden, } \\
\text { men, born in } \\
1923-1945\end{array}$ & Case control & $\begin{array}{l}943 \text { cases, } \\
943 \text { controls }\end{array}$ & $\begin{array}{l}\text { Serum total } \\
\text { calcium }\end{array}$ & Prostate cancer & $\begin{array}{l}\text { OR: 1.34 } \\
(0.78-1.39) \\
\text { for highest } \\
\text { versus lowest } \\
\text { quartile }\end{array}$ & $\begin{array}{l}\text { Matched on BMI, educational } \\
\text { level, alcohol consumption, } \\
\text { and smoking. }\end{array}$ \\
\hline $\begin{array}{l}\text { Schwartz, } \\
\text { 2012 [160] }\end{array}$ & $\begin{array}{l}\text { National Health } \\
\text { and Nutrition } \\
\text { Examination } \\
\text { Survey III } \\
\text { (NHANES III), } \\
\text { USA, age 18+ }\end{array}$ & Cohort & $\begin{array}{l}6707 \text { at baseline, } \\
49 \text { events, } \\
1069327 \\
\text { person-months }\end{array}$ & $\begin{array}{l}\text { Serum total } \\
\text { calcium }\end{array}$ & $\begin{array}{l}\text { Prostate cancer } \\
\text { mortality }\end{array}$ & $\begin{array}{l}\text { HR: 1.50 } \\
(95 \% \text { Cl: } \\
1.04-2.17) \\
\text { for every unit }\end{array}$ & $\begin{array}{l}\text { Adjusted for age and BMI, } \\
\text { serum albumin, and serum } \\
25-O H D \text { and account for } \\
\text { survey weights and the complex } \\
\text { sampling design of NHANES III } \\
\text { increase }\end{array}$ \\
\hline $\begin{array}{l}\text { Salem, } \\
\text { 2013 [161] }\end{array}$ & $\begin{array}{l}\text { Iran, men, mean } \\
\text { age 71.1 (cases) } \\
\text { and 66.5 (controls) }\end{array}$ & Case control & $\begin{array}{l}194 \text { cases, } \\
317 \text { controls }\end{array}$ & $\begin{array}{l}\text { Serum total } \\
\text { calcium }\end{array}$ & Prostate cancer & $\begin{array}{l}\text { OR: } \\
(0.12-0.27 \\
\text { for or highest } \\
\text { versus lowest } \\
\text { tertile }\end{array}$ & $\begin{array}{l}\text { Adjusted for age, body mass } \\
\text { index, occupation, educational } \\
\text { level, smoking, alcohol, family } \\
\text { history of prostate cancer, and } \\
\text { sex hormones. Similar results } \\
\text { with albumin-corrected calcium }\end{array}$ \\
\hline
\end{tabular}




\section{Conclusion}

Overall, more recent observational studies supported previous findings obtained in AMORIS, although no new results have been reported for serum fructosamine and inorganic phosphate with respect to cancer risk. A drawback of using serum markers in predicting risk of cancer is its potential fluctuations following other pathological conditions, resulting in non-specificity and imprecision of associations observed. Utilisation of multiple combination markers may provide benefit from enhanced specificity in relation to cancer, as well as repeated or serial measurements instead of a single measurement. Associations with other diseases may also necessitate further analytical strategies addressing effects of serum metabolic markers on competing events in addition to cancer. Finally, delineating the role of serum metabolic markers may generate valuable information to complement emerging clinical studies on preventive effects of drugs and supplements targeting metabolic disorders against cancer.

\section{Acknowledgment}

We would like to thank Dr Ingmar Jungner, Prof Göran Walldius, and Prof Niklas Hammar from the Institute of Environmental Medicine at the Karolinska Institute (Stockholm) for having provided us with the amazing opportunity to study cancer development in the AMORIS database.

This research was supported by the Experimental Cancer Medicine Centre at King's College London, the Swedish Research Council for Health, Working Life and Welfare, and also by the National Institute for Health Research (NIHR) Biomedical Research Centre based at Guy's and St Thomas' NHS Foundation Trust, and King's College London. The views expressed are those of the author(s) and not necessarily those of the NHS, the Swedish Research Council, the NIHR, or the Department of Health.

\section{References}

1. Jungner I et al (1998) Apolipoprotein B and A-I values in 147576 Swedish males and females, standardized according to the World Health Organization-International Federation of Clinical Chemistry First International Reference Materials Clin Chem 44(8 Pt 1) 1641-9 PMID: 9702950

2. Jungner I et al (2006) Does low-density lipoprotein size add to atherogenic particle number in predicting the risk of fatal myocardial infarction? Am J Cardiol 97(7) 943-6 DOI: 10.1016/j.amjcard.2005.10.062 PMID: 16563891

3. Jungner I et al (1992) Apolipoprotein B and A-I in relation to serum cholesterol and triglycerides in $\mathbf{4 3 , 0 0 0 ~ S w e d i s h ~ m a l e s ~ a n d ~}$ females Int J Clin Lab Res 21(3) 247-55 DOI: 10.1007/BF02591655 PMID: 1591376

4. Walldius G et al (2001) High apolipoprotein B, low apolipoprotein A-I, and improvement in the prediction of fatal myocardial infarction (AMORIS study): a prospective study Lancet 358(9298) 2026-33 DOI: 10.1016/S0140-6736(01)07098-2

5. Gaur A et al (2013) Iron metabolism and risk of cancer in the Swedish AMORIS study Cancer Causes Control 24(7) 1393-402 DOI: 10.1007/s10552-013-0219-8 PMID: 23649231 PMCID: 3675271

6. Melvin JC et al (2012) Gamma-glutamyl transferase and C-reactive protein as alternative markers of metabolic abnormalities and their associated comorbidites: a prospective cohort study Int J Mol Epidemiol Genet 3(4) 276-85 PMID: 23205179 PMCID: $\underline{3508539}$

7. Melvin JC et al (2012) Lipid profiles and risk of breast and ovarian cancer in the Swedish AMORIS study Cancer Epidemiol Biomarkers Prev 21(8) 1381-4 DOI: 10.1158/1055-9965.EPI-12-0188 PMID: 22593241

8. Seth D et al (2012) Lipid profiles and the risk of endometrial cancer in the Swedish AMORIS study Int J Mol Epidemiol Genet 3(2) 122-33 PMID: 22724049 PMCID: 3376923

9. Van Hemelrijck M et al (2010) Immunoglobulin E and cancer: a meta-analysis and a large Swedish cohort study Cancer Causes Control 21(10) 1657-67 DOI: 10.1007/s10552-010-9594-6 PMID: 20533084 
10. Van Hemelrijck M et al (2012) The interplay between lipid profiles, glucose, BMI and risk of kidney cancer in the Swedish AMORIS study Int J Cancer 130(9) 2118-28 DOI: 10.1002/ijc.26212

11. Van Hemelrijck M et al (2010) Prostate cancer risk in the Swedish AMORIS study: the interplay among triglycerides, total cholesterol, and glucose Cancer 117(10) 2086-95 DOI: 10.1002/cncr.25758

12. Van Hemelrijck $\mathrm{M}$ et al (2012)Biomarker-based score to predict mortality in persons aged $\mathbf{5 0}$ years and older: a new approach in the Swedish AMORIS study Int J Mol Epidemiol Genet 3(1) 66-76 PMID: 22493753 PMCID: 3316450

13. Van Hemelrijck $M$ et al (2011) Association between levels of $C$-reactive protein and leukocytes and cancer: three repeated measurements in the Swedish AMORIS study Cancer Epidemiol Biomarkers Prev 20(3) 428-37 DOI: 10.1158/1055-9965.EPI-101190 PMID: 21297038 PMCID: $\underline{3078551}$

14. Van Hemelrijck $M$ et al (2011) Low levels of apolipoprotein A-I and HDL are associated with risk of prostate cancer in the Swedish AMORIS study Cancer Causes Control 22(7) 1011-9 DOI: 10.1007/s10552-011-9774-z PMID: 21562751

15. Wulaningsih W et al (2012) Serum Lipids and the Risk of Gastrointestinal Malignancies in the Swedish AMORIS Study J Cancer Epidemiol 792034 PMID: 22969802 PMCID: $\underline{3437288}$

16. Wulaningsih $\mathrm{W}$ et al (2013) Serum glucose and fructosamine in relation to risk of cancer PLoS One 8(1) e54944 DOI: $10.1371 /$ journal.pone.0054944 PMID: 23372798 PMCID: $\underline{3556075}$

17. Wulaningsih W et al (2013) Inorganic phosphate and the risk of cancer in the Swedish AMORIS study BMC Cancer 13257 DOI: 10.1186/1471-2407-13-257 PMID: 23706176 PMCID: $\underline{3664604}$

18. Wulaningsih W et al (2013) Serum calcium and risk of gastrointestinal cancer in the Swedish AMORIS study BMC Public Health 13(1) 663 DOI: 10.1186/1471-2458-13-663 PMID: 23866097 PMCID: $\underline{3729677}$

19. Van Hemelrijck $M$ et al (2011) Gamma-glutamyltransferase and risk of cancer in a cohort of 545,460 persons - the Swedish AMORIS study Eur J Cancer 47(13) 2033-41 DOI: 10.1016/j.ejca.2011.03.010 PMID: 21486691

20. Van Hemelrijck $M$ et al (2012) Serum calcium and incident and fatal prostate cancer in the Swedish AMORIS study Cancer Causes Control 23(8) 1349-58 DOI: 10.1007/s10552-012-0015-x PMID: 22710746

21. Lambe $\mathrm{M}$ et al (2011) Impaired glucose metabolism and diabetes and the risk of breast, endometrial, and ovarian cancer Cancer Causes Control 22(8) 1163-71 DOI: 10.1007/s10552-011-9794-8 PMID: 21688131

22. Van Hemelrijck $M$ et al (2011) Risk of prostate cancer is not associated with levels of C-reactive protein and other commonly used markers of inflammation Int J Cancer 129(6) 1485-92 DOI: 10.1002/ijc.25773 PMID: 21792885

23. Hager MH, Solomon KR and Freeman MR (2006) The role of cholesterol in prostate cancer Curr Opin Clin Nutr Metab Care 9(4) 379-85 DOI: 10.1097/01.mco.0000232896.66791.62 PMID: 16778565

24. Sniderman AD and Faraj M (2007) Apolipoprotein B, apolipoprotein A-I, insulin resistance and the metabolic syndrome Curr Opin Lipidol 18(6) 633-7 DOI: 10.1097/MOL.0b013e3282f0dd33 PMID: 17993808

25. Guo S, Wang Y, Zhou D and Li Z (2014) Significantly increased monounsaturated lipids relative to polyunsaturated lipids in six types of cancer microenvironment are observed by mass spectrometry imaging Sci Rep 45959 PMID: 25091112 PMCID: 4121604

26. Van de Sande T et al (2005) High-level expression of fatty acid synthase in human prostate cancer tissues is linked to activation and nuclear localization of Akt/PKB J Pathol 206(2) 214-9 DOI: 10.1002/path.1760 PMID: 15880754

27. Yang $Y$ et al (2011) Role of fatty acid synthase in gemcitabine and radiation resistance of pancreatic cancers Int $J$ Biochem Mol Biol 2(1) 89-98 PMID: 21331354 PMCID: $\underline{3039422}$ 
28. Sebastiani $\vee$ et al Fatty acid synthase is a marker of increased risk of recurrence in endometrial carcinoma Gynecol Oncol 92(1) 101-5 PMID: 14751145

29. Murai T (2014) Cholesterol lowering: role in cancer prevention and treatment. Biol Chem 396(1) 1-11 DOI: 10.1515/hsz-20140194 PMID: $\underline{25205720}$

30. Peck B and Schulze A (2014) Cholesteryl esters: fueling the fury of prostate cancer Cell Metabol 19(3) 350-2 DOI: 10.1016/j. cmet.2014.02.012

31. Krycer JR and Brown AJ (2013) Cholesterol accumulation in prostate cancer: a classic observation from a modern perspective Biochim Biophys Acta 1835(2) 219-29 PMID: 23357067

32. Dos Santos CR et al (2014) LDL-cholesterol signaling induces breast cancer proliferation and invasion Lipids Health Dis 1316 DOI: 10.1186/1476-511X-13-16 PMID: 24428917 PMCID: $\underline{3896822}$

33. Yue $\mathrm{S}$ and $\mathrm{Li} \mathrm{J}$ et al (2014) Cholesteryl ester accumulation induced by PTEN loss and PI3K/AKT activation underlies human prostate cancer aggressiveness Cell Metabol 19(3) 393-406 DOI: $10.1016 / \mathrm{j} . c m e t .2014 .01 .019$

34. Majumder PK and Sellers WR (2005) Akt-regulated pathways in prostate cancer Oncogene 24(50) 7465-74 DOI: 10.1038/ sj.onc.1209096 PMID: 16288293

35. Kitahara CM et al (2011) Total cholesterol and cancer risk in a large prospective study in Korea J Clinic Oncol 29(12) 1592-8 DOI: $\underline{10.1200 / \mathrm{JCO} .2010 .31 .5200}$

36. Kok DE et al (2011) Blood lipid levels and prostate cancer risk; a cohort study Prostate Cancer Prostatic Dis 14(4) 340-5 DOI: $\underline{10.1038 / \text { pcan.2011.30 PMID: } 21727905}$

37. Mondul AM et al (2011) Serum total and HDL cholesterol and risk of prostate cancer Cancer Causes Control 22(11) 1545-52 DOI: $10.1007 / \mathrm{s} 10552-011-9831-7$ PMID: 21915616 PMCID: $\underline{3500884}$

38. Shafique $\mathrm{K}$ et al (2012) Cholesterol and the risk of grade-specific prostate cancer incidence: evidence from two large prospective cohort studies with up to 37 years' follow up BMC Cancer 1225 DOI: 10.1186/1471-2407-12-25 PMID: 22260413 PMCID: 3271031

39. Haggstrom C et al (2012) Prospective study on metabolic factors and risk of prostate cancer Cancer 118(24) 6199-206 DOI: $10.1002 /$ cncr.27677 PMID: 23090855

40. Jacobs EJ et al (2012) Plasma total, LDL, and HDL cholesterol and risk of aggressive prostate cancer in the Cancer Prevention Study II Nutrition Cohort Cancer Causes Control 23(8) 1289-96 DOI: 10.1007/s10552-012-0006-y PMID: 22692409

41. Agnoli $C$ et al (2014) Colorectal cancer risk and dyslipidemia: a case-cohort study nested in an Italian multicentre cohort Cancer Epidemiol 38(2) 144-51 DOI: 10.1016/j.canep.2014.02.002 PMID: 24636241

42. Kim HS et al (2013) [Prevalence and risk factors of colorectal adenoma in 14,932 koreans undergoing screening colonoscopy] Korean J Gastroenterol 62(2) 104-10 DOI: 10.4166/kig.2013.62.2.104 PMID: 23981944

43. Van Duijnhoven FJ et al (2011) Blood lipid and lipoprotein concentrations and colorectal cancer risk in the European Prospective Investigation into Cancer and Nutrition Gut 60(8) 1094-102 DOI: 10.1136/qut.2010.225011 PMID: 21383385

44. Hu NC et al Stepwise relationship between components of metabolic syndrome and risk of colorectal adenoma in a Taiwanese population receiving screening colonoscopy J Formos Med Assoc 110(2) 100-8 PMID: 21377064

45. Aleksandrova $\mathrm{K}$ et al (2011) Metabolic syndrome and risks of colon and rectal cancer: the European prospective investigation into cancer and nutrition study Cancer Prev Res 4(11) 1873-83 DOI: 10.1158/1940-6207.CAPR-11-0218

46. Stocks $\mathrm{T}$ et al (2011) Metabolic factors and the risk of colorectal cancer in $\mathbf{5 8 0 , 0 0 0}$ men and women in the metabolic syndrome and cancer project (Me-Can) Cancer 117(11) 2398-407 DOI: 10.1002/cncr.25772 PMID: 24048787 
47. Agnoli $C$ et al (2010) Metabolic syndrome and postmenopausal breast cancer in the ORDET cohort: a nested case-control study Nutr Metab Cardiovasc Dis 20(1) 41-8 DOI: 10.1016/j.numecd.2009.02.006 PMCID: 2819536

48. Wu Q et al (2012) Metabolic syndrome components and risk factors for pancreatic adenocarcinoma: a case-control study in China Digestion 86(4) 294-301 DOI: 10.1159/000341397 PMID: 23095334

49. His M et al (2014) Prospective associations between serum biomarkers of lipid metabolism and overall, breast and prostate cancer risk Eur J Epidemiol 29(2) 119-32 DOI: 10.1007/s10654-014-9884-5 PMID: 24519551

50. Bjorge T et al (2011) Metabolic risk factors and ovarian cancer in the Metabolic Syndrome and Cancer project Int J Epidemiol 40(6) 1667-77 DOI: 10.1093/ije/dyr130 PMID: 21984693

51. Jiang $\mathrm{R}$ et al Elevated apolipoprotein A-l levels are associated with favorable prognosis in metastatic nasopharyngeal carcinoma Med Oncol 31(8) 80 PMID: 25023050

52. Renehan AG et al (2008) Body-mass index and incidence of cancer: a systematic review and meta-analysis of prospective observational studies Lancet 371(9612) 569-78 DOI: 10.1016/S0140-6736(08)60269-X PMID: 18280327

53. Moon $\mathrm{H}$ et al (2014) Statins: protectors or pretenders in prostate cancer? Trends Endocrinol Metab 25(4) 188-96 DOI: 10.1016/j. tem.2013.12.007 PMID: 24462080

54. Lochhead P and Chan AT (2013) Statins and colorectal cancer Clin Gastroenterol Hepatol 11(2) 109-18 quiz e13-4. DOI: 10.1016/j. cgh.2012.08.037 PMCID: $\underline{3703461}$

55. Li X et al (2014) Fatostatin displays high antitumor activity in prostate cancer by blocking SREBP-regulated metabolic pathways and androgen receptor signaling Mol Cancer Therap 13(4) 855-66 DOI: 10.1158/1535-7163.MCT-13-0797

56. Jacobs EJ and Gapstur SM (2009) Cholesterol and cancer: answers and new questions Cancer Epidemiol Biomarkers Prev 18(11) 2805-6 DOI: 10.1158/1055-9965.EPI-09-1027 PMID: 19887583

57. Millan J et al (2009) Lipoprotein ratios: Physiological significance and clinical usefulness in cardiovascular prevention Vasc Health Risk Manag 5 757-65 PMID: 19774217 PMCID: 2747394

58. Pintilie M (2007) Analysing and interpreting competing risk data Stat Med 26(6) 1360-7 DOI: $10.1002 / \mathrm{sim} .2655$

59. Grote VA, Becker S and Kaaks R(2010) Diabetes mellitus type 2 - an independent risk factor for cancer? Exp Clin Endocrinol Diabetes 118(1) 4-8 DOI: 10.1055/s-0029-1243193 PMID: 20127570

60. True MW (2009) Circulating biomarkers of glycemia in diabetes management and implications for personalized medicine J Diabetes Sci Technol 3(4) 743-7 PMCID: 2769973

61. Novosyadlyy R et al (2010) Insulin-mediated acceleration of breast cancer development and progression in a nonobese model of type 2 diabetes Cancer Res 70(2) 741-51 DOI: 10.1158/0008-5472.CAN-09-2141 PMID: 20068149 PMCID: 2946167

62. Gallagher EJ, LeRoith D and Minireview IGF, Insulin, and Cancer Endocrinol 152(7) 2546-51

63. Sparvero LJ et al (2009) RAGE (Receptor for Advanced Glycation Endproducts), RAGE ligands, and their role in cancer and inflammation J Transl Med 717 DOI: 10.1186/1479-5876-7-17 PMID: 19292913 PMCID: 2666642

64. Kasper JS and Giovannucci E (2006) A meta-analysis of diabetes mellitus and the risk of prostate cancer Cancer Epidemiol Biomarkers Prev 15(11) 2056-62 DOI: 10.1158/1055-9965.EPI-06-0410 PMID: 17119028

65. Hammarsten J and Hogstedt B (2005) Hyperinsulinaemia: a prospective risk factor for lethal clinical prostate cancer Eur J Cancer

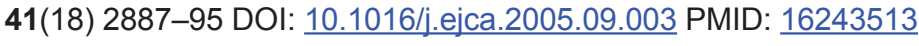

66. Stocks $T$ et al (2007) Insulin resistance is inversely related to prostate cancer: a prospective study in Northern Sweden Int $J$ Cancer 120(12) 2678-86 DOI: $\underline{10.1002 / i i j c .22587 ~ P M I D: ~} 17278097$ 
67. Deming SL et al (2012) Melatonin pathway genes and breast cancer risk among Chinese women Breast Cancer Res Treat 132(2) 693-9 DOI: $10.1007 / \mathrm{s} 10549-011-1884-5$

68. Parekh $\mathrm{N}$ et al (2013) Metabolic dysregulation of the insulin-glucose axis and risk of obesity-related cancers in the Framingham heart study-offspring cohort (1971-2008) Cancer Epidemiol Biomarkers Prev 22(10) 1825-36 DOI: 10.1158/1055-9965.EPI-13-0330 PMID: $\underline{24064521}$

69. Friedenreich CM et al (2012) Case-control study of markers of insulin resistance and endometrial cancer risk Endocr Relat Cancer 19(6) 785-92 DOI: 10.1530/ERC-12-0211

70. Ulmer $\mathrm{H}$ et al (2012) Metabolic risk factors and cervical cancer in the metabolic syndrome and cancer project (Me-Can) Gynecol Oncol 125(2) 330-5 DOI: 10.1016/j.ygyno.2012.01.052 PMID: 22330614

71. Borena $W$ et al (2012) Metabolic risk factors and primary liver cancer in a prospective study of $\mathbf{5 7 8 , 7 0 0}$ adults Int $J$ Cancer 131(1) 193-200 DOI: 10.1002/ijc.26338

72. Johansen $\mathrm{D}$ et al (2010) Metabolic factors and the risk of pancreatic cancer: a prospective analysis of almost 580,000 men and women in the Metabolic Syndrome and Cancer Project Cancer Epidemiol Biomarkers Prev 19(9) 2307-17 DOI: 10.1158/1055-9965. EPI-10-0234 PMID: 20826833

73. Almquist $\mathrm{M}$ et al (2011) Metabolic factors and risk of thyroid cancer in the Metabolic syndrome and Cancer project (Me-Can) Cancer Causes Control 22(5) 743-51 DOI: 10.1007/s10552-011-9747-2 PMID: 21380729

74. Boyle P et al (2013) Blood glucose concentrations and breast cancer risk in women without diabetes: a meta-analysis Eur $J$ Nutr 52(5) 1533-40 DOI: 10.1007/s00394-012-0460-z

75. Giovannucci E et al (2010) Diabetes and cancer: a consensus report Diabetes Care 33(7) 1674-85 DOI: $\underline{10.2337 / \mathrm{dc} 10-0666}$ PMID: 20587728 PMCID: 2890380

76. Zhang ZJ et al (2014) Reduced risk of lung cancer with metformin therapy in diabetic patients: a systematic review and meta-analysis Am J Epidemiol 180(1) 11-4 DOI: 10.1093/aje/kwu124 PMID: 24920786

77. Singh S et al (2013) Antidiabetic medications and the risk of colorectal cancer in patients with diabetes mellitus: a systematic review and meta-analysis Cancer Epidemiol Biomarkers Prev 22(12) 2258-68 DOI: 10.1158/1055-9965.EPI-13-0429 PMID: $\underline{24042261}$

78. Noto $\mathrm{H}$ et al (2012) Cancer risk in diabetic patients treated with metformin: a systematic review and meta-analysis PLoS One 7(3) e33411 DOI: 10.1371/journal.pone.0033411 PMID: 22448244 PMCID: $\underline{3308971}$

79. Hosono $\mathrm{K}$ et al (2010) Metformin suppresses azoxymethane-induced colorectal aberrant crypt foci by activating AMP-activated protein kinase Mol Carcinog 49(7) 662-71 DOI: 10.1002/mc.20637 PMID: 20564343

80. Kabat GC et al (2009) Repeated measures of serum glucose and insulin in relation to postmenopausal breast cancer Int $J$ Cancer 125(11) 2704-10 DOI: 10.1002/ijc.24609 PMID: 19588485

81. Schafer M and Werner S (2008) Cancer as an overhealing wound: an old hypothesis revisited Nat Rev Mol Cell Biol 9(8) 628-38 DOI: $\underline{10.1038 / \mathrm{nrm} 2455}$ PMID: 18628784

82. Grivennikov SI, Greten FR and Karin M (2010) Immunity, inflammation, and cancer Cell 140(6)883-99 DOI: 10.1016/j.cell.2010.01.025 PMID: 20303878 PMCID: $\underline{2866629}$

83. Han Y et al (2011) Prognostic role of C-reactive protein in breast cancer: a systematic review and meta-analysis Intl J Biol Markers 26(4) 209-15

84. Hu Q et al (2014) The prognostic value of C-reactive protein in renal cell carcinoma: A systematic review and meta-analysis Urol Oncol 32(1) 50 e1-8 DOI: 10.1016/j.urolonc.2013.07.016 
85. Chen $\mathrm{M}$ et al (2013) Systematic review and meta-analysis of tumor biomarkers in predicting prognosis in esophageal cancer BMC Cancer 13(1) 539 DOI: 10.1186/1471-2407-13-539 PMID: 24206575 PMCID: $\underline{3828582}$

86. McMillan DC (2009) Systemic inflammation, nutritional status and survival in patients with cancer Curr Opin Clin Nutr Metab Care 12(3) 223-6 DOI: 10.1097/MCO.0b013e32832a7902 PMID: 19318937

87. Ye B et al (2003) Haptoglobin-alpha subunit as potential serum biomarker in ovarian cancer: identification and characterization using proteomic profiling and mass spectrometry Clin Cancer Res 9(8) 2904-11 PMID: 12912935

88. Alvarez-Blasco F et al (2009) Role of haptoglobin in polycystic ovary syndrome (PCOS), obesity and disorders of glucose tolerance in premenopausal women PLoS One 2009; 4(5):e5606. DOI: 10.1371/journal.pone.0005606

89. Guo YZ et al (2013) Association between C-reactive protein and risk of cancer: a meta-analysis of prospective cohort studies Asian Pac J cancer Prev 14(1) 243-8 DOI: 10.7314/APJCP.2013.14.1.243 PMID: 23534731

90. Lee S et al (2011) High-sensitivity C-reactive protein and cancer J Epidemiol 21(3) 161-8 DOI: 10.2188/jea.JE20100128 PMID: 21368452 PMCID: 3899404

91. Shiels MS et al (2013) Circulating inflammation markers and prospective risk for lung cancer J Natl Cancer Inst 105(24) 1871-80 DOI: 10.1093/inci/dit309 PMID: 24249745 PMCID: $\underline{3888091}$

92. Xu M et al (2013) Serum C-reactive protein and risk of lung cancer: a case-control study Med Oncol 30(1) 319 DOI: $10.1007 /$ s12032-012-0319-4

93. Dossus $L$ et al $C$-reactive protein and postmenopausal breast cancer risk: results from the E3N cohort study Cancer Causes Control 25(4) 533-9 PMID: 24504436

94. Toriola AT et al (2013) Biomarkers of inflammation are associated with colorectal cancer risk in women but are not suitable as early detection markers Int J Cancer 132(11) 2648-58 DOI: 10.1002/ijc.27942 PMCID: 3609926

95. Trabert B et al (2014) Pre-diagnostic serum levels of inflammation markers and risk of ovarian cancer in the Prostate, Lung, Colorectal and Ovarian Cancer (PLCO) Screening Trial Gynecol Oncol DOI: 10.1016/j.ygyno.2014.08.025 PMID: 25158036 PMCID: $\underline{4254357}$

96. Aleksandrova $\mathrm{K}$ et al (2014) Inflammatory and metabolic biomarkers and risk of liver and biliary tract cancer Hepatology 60(3) 858-71 DOI: 10.1002/hep.27016 PMID: 24443059 PMCID: 4231978

97. Toriola AT et al (2011) Changes in pre-diagnostic serum C-reactive protein concentrations and ovarian cancer risk: a longitudinal study Ann Oncol 22(8) 1916-21 DOI: 10.1093/annonc/mdq694 PMID: 21292643

98. Bao Y et al (2013) Inflammatory plasma markers and pancreatic cancer risk: a prospective study of five U.S. cohorts Cancer Epidemiol Biomarkers Prev 22(5) 855-61 DOI: 10.1158/1055-9965.EPI-12-1458 PMID: 23462920 PMCID: 3650127

99. Grote VA et al (2012) Inflammation marker and risk of pancreatic cancer: a nested case-control study within the EPIC cohort Br J Cancer 106(11) 1866-74 PMID: 22617158 PMCID: $\underline{3364108}$

100. Toriola AT et al (2013) Prediagnostic circulating markers of inflammation and risk of prostate cancer Int $J$ Cancer 133(12) 2961-7 PMID: 23754532

101. Calboli FC et al (2011) Prediagnostic plasma IgE levels and risk of adult glioma in four prospective cohort studies $J$ Natl Cancer Inst 103(21) 1588-95 DOI: 10.1093/jnci/dj3361 PMID: 22010181 PMCID: $\underline{3206038}$

102. Schlehofer B et al (2011) Primary brain tumours and specific serum immunoglobulin E: a case-control study nested in the European Prospective Investigation into Cancer and Nutrition cohort Allergy 66(11) 1434-41 DOI: 10.1111/j.1398-9995.2011.02670.x PMID: $\underline{21726235}$

103. Schwartzbaum J et al (2012) Association between prediagnostic IgE levels and risk of glioma J Natl Cancer Inst 104(16) 1251-9 DOI: 10.1093/jnci/djs315 PMID: 22855780 PMCID: 3424222 
104.Wiemels $\mathrm{JL}$ et al (2011) Reduced allergy and immunoglobulin E among adults with intracranial meningioma compared to controls Int J Cancer 129(8) 1932-9 DOI: 10.1002/ijc.25858 PMID: 21520030 PMCID: $\underline{3337969}$

105. Hanahan D and Weinberg RA (2011) Hallmarks of cancer: the next generation Cell 144(5) 646-74 DOI: 10.1016/j.cell.2011.02.013 PMID: $\underline{21376230}$

106. Prizment AE et al (2013) Plasma C-reactive protein, genetic risk score, and risk of common cancers in the atherosclerosis risk in communities study Cancer Causes Control 24(12) 2077-87 DOI: 10.1007/s10552-013-0285-y PMID: 24036889 PMCID: $\underline{3836434}$

107. Su HX et al (2014) Mutations of C-reactive protein (CRP) -286 SNP, APC and p53 in colorectal cancer: implication for a CRP-Wnt crosstalk PLoS One 9(7) e102418 DOI: 10.1371/journal.pone.0102418 PMID: 25025473 PMCID: 4099363

108. Pine SR et al (2011) Increased levels of circulating interleukin 6, interleukin 8, C-reactive protein, and risk of lung cancer J Natl Cancer Inst 103(14) 1112-22 DOI: 10.1093/jnci/djr216 PMID: 21685357 PMCID: $\underline{3139587}$

109. Dowling P et al (2012) Analysis of acute-phase proteins, AHSG, C3, CLI, HP and SAA, reveals distinctive expression patterns associated with breast, colorectal and lung cancer Int J Cancer 131(4) 911-23 DOI: 10.1002/ijc.26462

110. Aleksandrova $\mathrm{K}$ et al (2014) Biomarker patterns of inflammatory and metabolic pathways are associated with risk of colorectal cancer: results from the European Prospective Investigation into Cancer and Nutrition (EPIC) Eur J Epidemiol 29(4) 261-75. DOI: $\underline{10.1007 / s 10654-014-9901-8}$ PMID: $\underline{24791703}$

111. Choi J, Liu RM and Forman HJ (1997) Adaptation to oxidative stress: quinone-mediated protection of signaling in rat lung epithelial L2 cells Biochem Pharmacol 53(7) 987-93 DOI: 10.1016/S0006-2952(96)00867-2 PMID: 9174112

112. Targher $G$ (2010) Elevated serum gamma-glutamyltransferase activity is associated with increased risk of mortality, incident type 2 diabetes, cardiovascular events, chronic kidney disease and cancer - a narrative review Clin Chem Lab Med 48(2) 147-57 DOI: $10.1515 / C C L M .2010 .031$

113. Strasak AM et al (2010) Prospective study of the association of serum gamma-glutamyltransferase with cervical intraepithelial neoplasia III and invasive cervical cancer Cancer Res 70(9) 3586-93 DOI: 10.1158/0008-5472.CAN-09-3197 PMID: 20388786

114. Strasak AM et al (2008) Prospective study of the association of gamma-glutamyltransferase with cancer incidence in women Int J Cancer 123(8) 1902-6 DOI: 10.1002/ijc.23714 PMID: 18688855

115. Strasak AM et al (2008) Association of gamma-glutamyltransferase and risk of cancer incidence in men: a prospective study Cancer Res 68(10) 3970-7 DOI: 10.1158/0008-5472.CAN-07-6686 PMID: 18483283

116. Fentiman I (2012) Gamma-glutamyl transferase: risk and prognosis of cancer Br J Cancer 106(9) 1467 DOI: $\underline{10.1038 / b j c .2012 .128}$ PMID: 22531718 PMCID: $\underline{3341856}$

117. Fentiman I and Allen D (2010) y-Glutamyl transferase and breast cancer risk Br J Cancer 103(1) 90-3 DOI: 10.1038/sj.bjc.6605719 PMID: 20517309 PMCID: 2905293

118. Strasak AM et al (2008) Association of Y-glutamyltransferase and risk of cancer incidence in men: a prospective study Cancer Res 68(10) 3970-7 DOI: 10.1158/0008-5472.CAN-07-6686 PMID: 18483283

119. Hu G et al (2008) Joint effects of coffee consumption and serum gamma-glutamyltransferase on the risk of liver cancer Hepatology 48(1) 129-36 DOI: 10.1002/hep.22320 PMID: 18537182

120. He W-z et al (2013) Gamma-glutamyl transpeptidase level is a novel adverse prognostic indicator in human metastatic colorectal cancer Colorectal Dis 15(8) e443-e52. DOI: 10.1111/codi.12258 PMID: 23621885

121.Zhang J-B et al (2011) Prognostic significance of serum gamma-glutamyl transferase in patients with intermediate hepatocellular carcinoma treated with transcatheter arterial chemoembolization Eur J Gastroenterol Hepatol 23(9) 787-93 DOI: 10.1097/ MEG.0b013e32834902dd PMID: 21730869 
122. Seebacher $V$ et al (2012) Prognostic significance of gamma-glutamyltransferase in patients with endometrial cancer: a multicentre trial Br J Cancer 106(9) 1551-5 DOI: 10.1038/bjc.2012.16 PMID: 22315051 PMCID: $\underline{3341855}$

123. Tsuboya T et al (2012) Gamma-glutamyltransferase and cancer incidence: the Ohsaki Cohort Study J Epidemiol 22(2) 144 DOI: 10.2188/jea.JE20110071 PMID: 22277791 PMCID: $\underline{3798593}$

124. Hernaez R et al (2013) Elevated ALT and GGT predict all-cause mortality and hepatocellular carcinoma in Taiwanese male: a case-cohort study Hepatology Int/ 7(4) 1040-9 DOI: 10.1007/s12072-013-9476-6

125. Grimm C et al (2013) Association of gamma-glutamyltransferase with severity of disease at diagnosis and prognosis of ovarian cancer Br J Cancer 109(3) 610-4 DOI: 10.1038/bjc.2013.323 PMID: 23921280 PMCID: 3738124

126. Edlinger $\mathrm{M}$ et al (2013) Lifestyle-related biomarkers and endometrial cancer survival: Elevated gamma-glutamyltransferase as an important risk factor Cancer Epidemiol 37(2) 156-61 DOI: 10.1016/j.canep.2012.12.003 PMID: 23295001

127. Yin X et al (2013) Elevation of serum c-glutamyltransferase as a predictor of aggressive tumor behaviors and unfavorable prognosis in patients with intrahepatic cholangiocarcinoma: analysis of a large monocenter study 25(12) 1408-14 PMID: $\underline{23839159}$

128. Hofbauer SL et al (2014) Pretherapeutic gamma-glutamyltransferase is an independent prognostic factor for patients with renal cell carcinoma Br J Cancer 111(8) 1526-31 DOI: 10.1038/bjc.2014.450 PMID: 25117808 PMCID: $\underline{4200090}$

129. Long $Y$ et al (2014) Gamma-glutamyltransferase predicts increased risk of mortality: A systematic review and meta-analysis of prospective observational studies. Free radical research 48(6) 716-28 PMID: 24684379

130. Kunutsor SK et al (2014) Gamma glutamyltransferase, alanine aminotransferase and risk of cancer: Systematic review and meta-analysis Intl J Cancer 136(5) 1162-70 DOI: 10.1002/ijc.29084

131. Kunutsor SK et al (2014) Liver enzymes and risk of all-cause mortality in general populations: a systematic review and metaanalysis Intl J Epidemiol 43(1) 187-201 DOI: 10.1093/ije/dyt192

132. Daubeuf $\mathrm{S}$ et al (2002) Enhanced resistance of HeLa cells to cisplatin by overexpression of gamma-glutamyltransferase Biochem Pharmacol 64(2) 207-16 DOI: 10.1016/S0006-2952(02)01118-8 PMID: 12123741

133. Godwin AK et al (1992) High resistance to cisplatin in human ovarian cancer cell lines is associated with marked increase of glutathione synthesis Proc Natl Acad Sci USA 89(7) 3070-4 DOI: $\underline{10.1073 / p n a s .89 .7 .3070 ~ P M I D: ~} \underline{1348364}$ PMCID: $\underline{48805}$

134. Rajpert-De Meyts E et al (1992) Transfection with gamma-glutamyl transpeptidase enhances recovery from glutathione depletion using extracellular glutathione Toxicol Appl Pharmacol 114(1) 56-62 DOI: 10.1016/0041-008X(92)90096-B PMID: 1350117

135.Pompella $\mathrm{A}$ et al (2006) Expression of gamma-glutamyltransferase in cancer cells and its significance in drug resistance Biochem Pharmacol 71(3) 231-8 DOI: 10.1016/j.bcp.2005.10.005

136. Corti A et al (2010) Gamma-glutamyltransferase of cancer cells at the crossroads of tumor progression, drug resistance and drug targeting Anticancer Res 30(4) 1169-81 PMID: 20530424

137. Hanigan $\mathrm{MH}$ (1995) Expression of gamma-glutamyl transpeptidase provides tumor cells with a selective growth advantage at

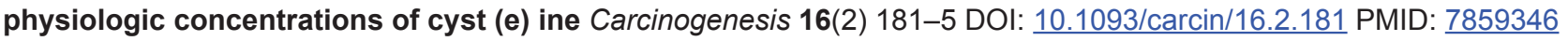

138. Beguin $Y$ et al (2014) Epidemiological and nonclinical studies investigating effects of iron in carcinogenesis-a critical review Critical Rev Oncol/Hematol 89(1) 1-15 DOI: 10.1016/j.critrevonc.2013.10.008

139. Weinberg ED (1996) The role of iron in cancer Eur J Cancer Prev 5(1) 19-36 PMID: 8664805

140. Lamy PJ, Durigova A and Jacot W (2014) Iron homeostasis and anemia markers in early breast cancer Clin Chim Acta 434(0) 34-40 DOI: $10.1016 /$ j.cca.2014.04.011 PMID: 24768787 
ecancer 2015, 9:555

141. Wen CP et al (2014) High serum iron is associated with increased cancer risk Cancer Res 74(22) 6589-97 DOI: 10.1158/0008-5472. CAN-14-0360 PMID: 25228650

142. Gilsing AM et al (2013) Dietary heme iron and the risk of colorectal cancer with specific mutations in KRAS and APC Carcinogenesis 34(12) 2757-66 DOI: $\underline{10.1093 / \text { carcin/bgt290 PMID: } 23983135}$

143. Ashmore JH et al (2013) Association of dietary and supplemental iron and colorectal cancer in a population-based study Eur J Cancer Prev 22(6) 506-11 DOI: 10.1097/CEJ.0b013e32836056f8 PMID: 23492957

144. Jakszyn $\mathrm{P}$ et al (2013) Meat and heme iron intake and esophageal adenocarcinoma in the European Prospective Investigation into Cancer and Nutrition study Int J Cancer 133(11) 2744-50 PMID: 23728954

145. Ruder EH et al (2014) Dietary iron, iron homeostatic gene polymorphisms and the risk of advanced colorectal adenoma and cancer Carcinogenesis 35(6) 1276-83 DOI: 10.1093/carcin/bgu028 PMID: 24536049 PMCID: 4043236

146. Fonseca-Nunes A, Jakszyn P and Agudo A (2014) Iron and cancer risk-a systematic review and meta-analysis of the epidemiological evidence Cancer Epidemiol Biomarkers Prev 23(1) 12-31 DOI: 10.1158/1055-9965.EPI-13-0733

147. Qiao L and Feng Y (2013) Intakes of heme iron and zinc and colorectal cancer incidence: a meta-analysis of prospective studies Cancer Causes Control 24(6) 1175-83 DOI: 10.1007/s10552-013-0197-x PMID: 23568532

148.van Veldhuisen DJ et al (2011) Anemia and iron deficiency in heart failure: mechanisms and therapeutic approaches Nat Rev Cardiol 8(9) 485-93 DOI: 10.1038/nrcardio.2011.77 PMID: 21629210

149. Martinsson A et al (2014) Anemia in the general population: prevalence, clinical correlates and prognostic impact Eur J Epidemiol 29(7) 489-98 DOI: 10.1007/s10654-014-9929-9 PMID: 24952166

150.Peacock M (2015) Calcium metabolism in health and disease Clin J Am Soc Nephrol 5 Suppl 1S23-30 DOI: 10.2215/ CJN.05910809

151.Bringhurst F et al (2008) Bone and mineral metabolism in health and disease In: Fauci A et al ed Harrrion's Prinicples of InternalMedicine New York: McGraw-Hill

152. Takeda E et al (2004) Inorganic phosphate homeostasis and the role of dietary phosphorus J Cell Mol Med 8(2) 191-200 DOI: $\underline{10.1111 / j .1582-4934.2004 . t b 00274 . x}$ PMID: 15256067

153. Jacobs ET et al (2009) Vitamin D, calcium, and colorectal neoplasia: new insights on mechanisms of action Cancer Prev Res 2(3) 197-9 DOI: 10.1158/1940-6207.CAPR-09-0019

154. Lamprecht SA and Lipkin M (2003) Chemoprevention of colon cancer by calcium, vitamin D and folate: molecular mechanisms Nat Rev Cancer 3(8) 601-14 DOI: 10.1038/nrc1144 PMID: 12894248

155. Camalier CE et al (2010) Elevated phosphate activates $\mathbf{N}$-ras and promotes cell transformation and skin tumorigenesis Cancer Prev Res 3(3) 359-70 DOI: 10.1158/1940-6207.CAPR-09-0068

156. Jin $\mathrm{H}$ et al (2007) High dietary inorganic phosphate affects lung through altering protein translation, cell cycle, and angiogenesis in developing mice Toxicol Sci 100(1) 215-23 DOI: 10.1093/toxsci/kfm202 PMID: 17698515

157. Jin $\mathrm{H}$ et al (2008) Low dietary inorganic phosphate affects the brain by controlling apoptosis, cell cycle and protein translation J Nutr Biochem 19(1) 16-25 DOI: 10.1016/j.jnutbio.2006.12.021

158. Jin $\mathrm{H}$ et al (2009) High dietary inorganic phosphate increases lung tumorigenesis and alters Akt signaling Am J Respir Crit Care Med 179(1) 59-68 DOI: $\underline{10.1164 / \mathrm{rccm} .200802-3060 \mathrm{C} \text { PMCID: } 2615662}$

159. Brandstedt J et al (2012) Vitamin D, PTH, and calcium and the risk of prostate cancer: a prospective nested case-control study Cancer Causes Control 23(8) 1377-85 DOI: 10.1007/s10552-012-9948-3 PMID: 22706676 
160.Schwartz GG and Skinner HG (2012) A prospective study of total and ionized serum calcium and time to fatal prostate cancer Cancer Epidemiol Biomarkers Prev 21(10) 1768-73 DOI: 10.1158/1055-9965.EPI-12-0585 PMID: 22914529

161.Salem S et al (2013) Serum calcium concentration and prostate cancer risk: a multicenter study Nutr Cancer 65(7) 961-8 DOI: 10.1080/01635581.2013.806936 PMID: 24053657

162. Bristow SM et al (2013) Calcium supplements and cancer risk: a meta-analysis of randomised controlled trials $\mathrm{Br} \mathrm{J}$ Nutr $110(8)$ 1384-93 DOI: $10.1017 /$ S0007114513001050 PMID: 23601861

163. Keum $\mathrm{N}$ et al (2014) Calcium intake and colorectal cancer risk: dose-response meta-analysis of prospective observational studies Int J Cancer 135(8) 1940-8 DOI: 10.1002/ijc.28840 PMID: 24623471

164. Bergwitz C and Juppner H (2010) Regulation of phosphate homeostasis by PTH, vitamin D, and FGF23 Annu Rev Med 61 91-104 DOI: 10.1146/annurev.med.051308.111339 PMID: 20059333

165. Christakos S et al (2011) Vitamin D and intestinal calcium absorption Mol Cell Endocrinol 347(1-2) 25-9 DOI: 10.1016/j. mce.2011.05.038 PMID: 21664413 PMCID: $\underline{3405161}$ 